\title{
III. Aufbau der deutschen Verwaltung
}

\section{Die Personalpolitik der amerikanischen Militärregierung 1945}

Am Morgen des 19. April 1945, einen Tag nach dem Einmarsch der amerikanischen Truppen, saßen der langjährige Bürgermeister und Beigeordnete der Stadt Ansbach, Friedrich Böhner, und sein alter Vertrauter Friedrich Wilhelm Beuschel pünktlich an ihren Schreibtischen im Stadthaus. Kaiserreich, Weimarer Republik, NS-Zeit Beuschel und Böhner hatten im Ansbacher Stadthaus schon zwei Regimewechsel erlebt und dabei die Erfahrung machen können, daß die Kontinuität der Beamtenschaft von wechselnden politischen Machthabern kaum behelligt worden war. Selbst nach der Machtergreifung der Nationalsozialisten waren in den leitenden Positionen der Stadtverwaltung keine größeren Veränderungen eingetreten. Auch als Kreisleiter Richard Hänel im Mai 1934 den nationalliberalen Wilhelm Borkholder im Amt des Oberbürgermeisters ablöste, blieb im Ansbacher Stadthaus fast alles beim alten. Hänel, ein wenig durchsetzungsfähiger, in Verwaltungsdingen gänzlich unerfahrener kleiner Angestellter, der sich die neue Aufgabe selbst nicht zutraute und erst von der Partei dazu überredet werden mußte, arrangierte sich mit der alten, überwiegend nationalkonservativen Beamtenschaft, die 1933 fast geschlossen der NSDAP beigetreten war. Er hielt sogar bis Kriegsende an einigen stadtbekannten Freimaurern in leitenden Positionen fest ${ }^{1}$.

Im Stadthaus trafen Böhner und Beuschel am Morgen des 19. April fast alle maßgeblichen Beamten der Stadtverwaltung. Sie hatten der Anweisung der amerikanischen Militärregierung Folge geleistet, vorläufig auf ihren Posten zu bleiben und weitere Anordnungen abzuwarten. Das Zimmer von Oberbürgermeister Hänel war allerdings schon seit Wochen leer. Hänel hatte beim Herannahen der amerikanischen Truppen die Stadt verlassen. Seinen Stellvertreter Albert Böhm, ein Nationalsozialist mit dem Goldenen Parteiabzeichen, der als einziger „Alter Kämpfer“ in die höheren Ränge der Ansbacher Beamtenschaft aufgestiegen war, hatten die Amerikaner inhaftiert $^{2}$. Die Gespräche zwischen Beuschel, Böhner und ihren Kollegen kreisten am 19. April vor allem um die Frage: Wer würde ihr neuer Chef werden? Das Rätselraten währte nicht lange, dann stellten die Amerikaner den sozialdemokratischen Gymnasiallehrer Hans Schregle (Jg. 1890) als neuen Oberbürgermeister vor. „Am zweiten Tage nach dem Einmarsch der Amerikaner", so schilderte Schregle seine Ernennung später, „erschien bei mir oben, ich weiß noch nicht auf welchem Wege dieser sog. Jeep damals hinaufgekommen ist, ein amerikanischer Wagen. Ich war gerade im Wald spazieren, um mich etwas zu erholen. Es wurde hinterlassen, daß ich auf der Militärregierung erscheinen soll. Am nächsten Tage, früh morgens, begab ich mich zur Militärre- 
gierung ... Ich hatte einige Zeit zu warten, dann wurde ich in ein Zimmer des sog. Präsidialgebäudes geführt. Vor mir saßen einige amerikanische Herren. Undurchdringlich, hart waren ihre Mienen, und sie legten mir die Frage vor, ob ich geneigt wäre, Oberbürgermeister der Stadt Ansbach zu werden, worauf ich ihnen erklärte: nein. Ich könnte das nicht, ich fühlte mich dazu nicht in der Lage, ich hätte von Natur aus keine Neigung und keine Berufung zu einem solchen Amte, wäre nicht vorgebildet, verstünde nichts von der Administration, und im übrigen sagte ich, sei mir nur das einzige am Nationalsozialismus sympathisch gewesen, nämlich das Gesetz zur Wiederherstellung des Berufsbeamtentums ..., jenes Gesetz, das fordert, daß nur derjenige im Gegensatz zur Weimarer Zeit in ein hohes Amt kommen soll, der dazu fachliche berufliche Voraussetzungen erfüllt. Die amerikanischen Herren bestanden darauf.“

„Jetzt sind sie Town-Major von Ansbach“, mit diesen Worten wurde der Lehrer in sein neues Amt eingeführt. Schregle, vom Typ her eher Bohemien als Beamter, wäre unter normalen Umständen wohl kaum für das Amt des Oberbürgermeisters in Frage gekommen. Der hochgebildete Mann mit feinem Kunstverstand und fundiertem historischen Wissen hatte Kunstgeschichte und Germanistik studiert und sich im Kaiserreich in der Wandervogelbewegung engagiert. Seine akademischen Lehrer hatten ihm damals nahegelegt, die Hochschullaufbahn einzuschlagen, doch Schregle beließ es bei einer Dissertation über „Götz von Berlichingen“. In den zwanziger Jahren war er viel in der Welt umhergereist, von 1926 bis 1929 war der sportbegeisterte Lehrer auch Vorsitzender des 1. Fußballclubs Nürnberg, des berühmten „Club“, gewesen. Da er früh vor der nazistischen Gefahr gewarnt und unter anderem im „Erlanger Volksblatt" vom 27. Juni 1931 einen flammenden Artikel gegen Hitler geschrieben hatte, verfügten die Nationalsozialisten 1933 die Strafversetzung von Erlangen an das Ansbacher Carolinum. Dort bildete sich um ihn herum eine kleine Gruppe von Intellektuellen, zu der auch der wegen seines Widerstandes in der letzten Stunde schmählich hingerichtete Student Robert Limpert zählte. Schregle zögerte lange, ob er das Amt des Oberbürgermeisters von Ansbach annehmen sollte, das vor 1933 stets in der Hand von nationalliberalen oder konservativen Juristen gewesen war. Nur zu gut war dem Sozialdemokraten bekannt, daß die evangelische Honoratiorenschaft seine Ernennung nicht begrüßte. „Edelkommunist“, hieß er bald bei vielen Bürgern, die Schregle aber auch wegen seiner „falschen“ Konfession ablehnten. Denn weder die bayerischen Könige, die Bayerische Volkspartei, noch die NSDAP hatten gewagt, was die Amerikaner zu tun bereit waren: Einen Katholiken an die Spitze der Hochburg des fränkischen Protestantismus zu stellen ${ }^{4}$.

Schregle blieb freilich nur bis Oktober 1945 im Amt, dann berief ihn die Militärregierung zum Regierungspräsidenten von Ober- und Mittelfranken. Zu seinem Nachfolger wählte der Beratende Ausschuß der Stadt, in dem die SPD mit sechs, die Demokratische Partei mit vier, die CSU mit drei Sitzen und die KPD mit einem Sitz vertreten war, am 12. Oktober 1945 den Sozialdemokraten Ernst Körner (Jg. 1899). Die

3 Prot. der Gemeindeversammlung vom 19. September 1947, in: Stadtverwaltung Ansbach, EAP 026-20, Bd. 1.

4 Zu Schregle vgl. Fränkische Landeszeitung vom 6. April 1950 und 18. April 1955; schriftliche Mitteilung des 1. Fußballclubs Nürnberg vom 13. November 1983; Dr. Hans Schregle zum Gedāchtnis, in: Jahrbuch des Historischen Vereins für Mittelfranken, Bd. 86, Ansbach 1971/1972, S.428f. Zu Schregle, dessen Frau später der CSU beitrat, vgl. auch die Akte Schregle, in: US Army Intelligence and Security Command, Fort George G. Meade, Maryland. 
Wahl Körners konnte aus zwei Gründen als Sensation gelten: Kaum fünf Monate nach Kriegsende hatte sich das anfänglich große Mißtrauen von Col. Whitaker gegenüber „seinen“ Deutschen so weit verringert, daß er ihnen die Entscheidung über den neuen Oberbürgermeister selbst überließ. Aber obwohl der gelernte Sattler Körner ebensowenig wie Schregle ein Mann des nationalkonservativen Milieus war, gewann er im Ausschuß auch die Unterstützung der bürgerlichen Parteien, die in dem Gremium nicht ihrer wahren Stärke entsprechend vertreten waren. Sie stimmten mehr aus Verlegenheit für Körner, weil sie keinen eigenen unbelasteten Kandidaten präsentieren konnten, der Militärregierung gegenüber aber Eintracht demonstrieren wollten. Gleichwohl blieb Körner, ein tatkräftiger und redegewandter Mann, der im KZ Dachau schwere gesundheitliche Schäden erlitten hatte, ein Außenseiter in der Stadt ${ }^{5}$.

Die Aufgabe der amerikanischen Offiziere, Ersatz für die alten politisch belasteten Bürgermeister und Landräte zu finden, war nicht leicht und mit „Handbook“-Kenntnis allein nicht zu lösen. Das Handbuch stellte nur fest, daß kein ehemaliger Nationalsozialist für ein öffentliches Amt in Frage kam $^{6}$, sagte aber nicht, wer nach politischer Einstellung und beruflicher Qualifikation für einen wichtigen Posten geeignet war. Wie so oft konnten sich die Offiziere nur auf ihre Improvisationsfähigkeit und die Ratschläge von Deutschen stützen. Doch welche Deutschen waren vertrauenswürdig genug, daß man ihren Empfehlungen folgen konnte? Die Befreiten aus den Konzentrationslagern, Vertreter der Kirche, alte Funktionäre der Weimarer republikanischen Parteien, die vor 1933 den Nationalsozialisten getrotzt hatten? Außerdem war der Kreis der „geeigneten Männer“ denkbar klein. Manch einem, der das Zeug zum Landrat oder Bürgermeister gehabt hätte, war in den zurückliegenden Jahren der politischen und ideologischen Strapazierung die Lust an öffentlichem Engagement vergangen. Viele scheuten sich auch, ein Amt zu übernehmen, um nicht als Handlanger der Besatzungsmacht zu gelten.

Aus solchem Personalmangel hatten die Amerikaner am 4. Mai 1945 an die Spitze der Regierung von Ober- und Mittelfranken einen fast siebzigjährigen alten Beamten gestellt, den Geheimen Regierungs- und Ministerialrat a. D. Ernst Reichard, einen selbstbewußten und weltläufigen Juristen, der sich 1933 geweigert hatte, die Parteimitgliedschaft zu erwerben und daraufhin in den Ruhestand versetzt worden war. Es war noch ein Glücksfall, daß man in dem national-konservativen Beamten von altem Schrot und Korn einen Mann zur Verfügung hatte, der ein entschiedener Gegner des Nationalsozialismus gewesen war und doch langjährige Verwaltungserfahrung hatte. In den Augen von Walter L. Dorn, den seine im Auftrag von OSS unternommenen Inspektionsreisen im Juli 1945 auch nach Ansbach führten, war Reichard „der fähigste Regierungspräsident Bayerns“, an dessen demokratischer Gesinnung kein Zweifel erlaubt sei. „Er beeindruckte mich durch seine Intelligenz und seine gute Urteilsfähigkeit ... Er hat ausgezeichnete Kenntnisse und reiche Erfahrung“, schrieb Dorn ${ }^{7}$.

Ähnlich schwierig war die Lage in Fürth. Hier ernannte Captain Cofer den farblo-

3 Zu Körner vgl. Woller, Demokratiebereitschaft in der Provinz, S. 335-364.

6 Vgl. SHAEF, Handbook for Military Government in Germany - Prior to Defeat or Surrender, December 1944, 0. O., in: IfZ-Archiv, Dk 090.009.

7 Reichard war 1910 in die Verwaltung von Elsaß-Lothringen eingetreten, hatte nach dem Ersten Weltkrieg im Reichsfinanz- und Reichsernāhrungsministerium gearbeitet und war dann von 1931 bis 1933 stellvertretender Reichskommissar für die Osthilfe gewesen. Nach seiner Versetzung in den Ruhestand hatte er den Werberat der deutschen Wirtschaft geleitet und war bis 1938 Vizeprāsident des Internationalen Werberats 
sen Juristen Adolf Schwiening (Jg. 1882), der seit mehr als dreißig Jahren im Dienst der Stadt stand, zum neuen Stadtoberhaupt ${ }^{8}$. Zuvor hatte er sich mit den führenden Sozialdemokraten Hans Schmidt, Konrad Eberhard und Hans Rupprecht besprochen, die aber keinen Personalvorschlag aus ihrer Partei machen konnten oder sich nicht zu früh exponieren wollten. Hans Schmidt, der von den Nationalsozialisten entlassene frühere 3. Bürgermeister, hatte dann Schwiening ins Gespräch gebracht, an dem er „stets seine vornehme Ruhe, seinen Charakter und sein Können bewundert“ hatte9. Daß Schwiening sich 1937 der NSDAP angeschlossen hatte, trübte sein Urteil nicht. Auch der katholische Stadtpfarrer, zwei jüdische Rechtsanwälte und der Chef des Amtsgerichts hatten den früheren Stadtkämmerer trotz seiner nominellen NSDAPMitgliedschaft empfohlen. Cofer hatte den Mut, seine Anweisungen unbeachtet zu lassen und diesen Empfehlungen zu folgen, stieß dabei aber auf heftige Kritik des CIC, das einwandte: „Weil Schwiening seit 1937 Parteimitglied war, und weil er 1939 zum Stadtkämmerer ernannt wurde, und weil in Fürth viele andere Personen mit einem sehr viel saubereren politischen Hintergrund vorhanden sind, empfiehlt das CIC, Schwiening seines jetzigen Amtes zu entheben und stattdessen eine Person zu ernennen, die für die Gegner des NS-Regimes akzeptabler ist. “10 Auch politisch Verfolgte aus den Reihen der KPD liefen Sturm gegen Schwiening, der in Flugblättern und Handzetteln sogar als „Nazischwein" beschimpft wurde ${ }^{1}$. Der Chef der Fürther Militärregierung, ein eigenwilliger Mann, der sich auch nach den aufgeregten Pressemeldungen wegen der Entnazifizierungspannen in Aachen einen klaren Blick für die Verhältnisse im besetzten Deutschland bewahrte, suchte die vehementen Angriffe mit zahlreichen eidesstattlichen Erklärungen von Sozialdemokraten und kirchlichen Würdenträgern zu parieren, die Schwiening attestierten, daß er Gegner des NS-Regimes und Mitglied des oppositionellen Kreises um Gleixner und Gastreich gewesen sei, der im April auf eine kampflose Übergabe der Stadt hingewirkt hatte.

Die Kritik an Schwiening und Cofer flaute aber erst ab, als der kommissarische Oberbürgermeister im Herbst 1945 resignierte und seinem bisherigen Stellvertreter Hans Schmidt (Jg. 1872) Platz machte ${ }^{12}$. Schmidt war freilich eher eine Verlegenheits-

in Paris gewesen. 1939 ließ er sich in Ansbach nieder, im Herbst 1944 hatte ihn die Gestapo für einige Zeit im Stadtgefängnis festgesetzt. Vgl. Fränkische Landeszeitung vom 2. August 1956. Vgl. auch Det. für Oberund Mittelfranken an Commanding General, 3. US-Armee, 6. Mai 1945, in: NA, RG 260, 9/114-3/19. Dorn war vor allem über die Vorstellungen Reichards von der staatsrechtlichen Ausgestaltung des zukünftigen Deutschland erstaunt - Vorstellungen, die von den dezidierten Föderalisten an der Spitze der Münchener Landesregierung wohl kaum geteilt worden sind. Nach Meinung von Reichard sollte die bayerische Regierung die Abkopplung vom Reich nicht allzu weit treiben, da dies zur Katastrophe führen müsse. Er konnte sich zwar für eine gewisse Revision der Erzbergerschen Finanzreform aus den zwanziger Jahren erwärmen, wollte aber verhindert wissen, daß das Reich, wie in der Kaiserzeit, Kostgänger der Länder werde (Dorn an Harold and Chan, 17. Juni 1945, in: NA, RG 226, Europe-Africa Division, Records Relating to Outposts in Germany: Germany-letters, 3/1/45-26/6/45).

8 Schwiening war 1913 als 30jāhriger nach dem Studium der Rechtswissenschaften in den Dienst der Stadt Fürth getreten und 1917 zum rechtskundigen Magistratsrat aufgestiegen. Von 1919 bis 1945 war er berufsmäßiger Stadtrat, zeitweise Stadtratsvorstand, gewesen. Seit 1939 hatte er auch die Stadtkämmerei geleitet. Vgl. Fürther Nachrichten vom 3./4. August 1963.

9 Schmidt an Cofer, 24. Oktober 1945, in: NA, RG 260, 9/122-5/13.

10 Hodges (CIC) an Cofer, 4. August 1945, in: Ebenda.

"Schmidt an RegPräs, 14. März 1946, in: Stadtverwaltung Fürth, EAP 06.

12 Schmidt war schon um die Jahrhundertwende in die Fürther Gemeindeverwaltung eingetreten und hatte reiche Erfahrung in kommunalpolitischen Fragen. Von 1902 bis 1910 hatte er dem Gemeindekollegium, von 1910 bis 1918 dem Stadtmagistrat und von 1918 bis 1930 dem Stadtrat angehört, ehe er von 1930 bis 1933 das Amt des zweiten ehrenamtlichen Bürgermeisters bekleidete. Von 1903 bis 1934 hatte er außerdem die Allgemeine Ortskrankenkasse in Fürth geleitet. Vgl. Fürther Nachrichten vom 6. September 1950. 
lösung. Der 73jährige war den Anforderungen des Amts nur noch bedingt gewachsen und ließ Einsatz und Effizienz vermissen: „Um dem abzuhelfen, ist die Ernennung eines fähigen Oberbürgermeisters erforderlich“, hieß es bei der Militärregierung ${ }^{13}$. Schmidt, der sich die Erfüllung der schweren Pflichten, die ihm seine Stellung auferlegte, wohl selbst nicht mehr zutraute, ging bereits wenige Tage nach seiner Amtseinführung daran, einen Nachfolger aus seiner Partei für sich zu suchen. Keine leichte Aufgabe, denn das sozialdemokratische Milieu war in der NS-Zeit brüchig geworden ${ }^{14}$. Einige jüngere Genossen befanden sich noch in Gefangenschaft, Hans Rupprecht und Hans Teichmann fühlten sich zu alt, Konrad Eberhard war im September an einer Wurstvergiftung gestorben, der spätere Landtagsabgeordnete Fritz Gräßler und Willy Fischer, später Mitglied des Bundestags, liebäugelten wohl schon damals mit einer Karriere in der „großen“ Politik. Schmidt erinnerte sich schließlich an den langjährigen Genossen Hans Bornkessel (Jg. 1892), den früheren berufsmäßigen Stadtrat, der als unversöhnlicher NS-Gegner nach der Machtübernahme der Nationalsozialisten zunächst beurlaubt und 1934 zwangsweise in den Ruhestand versetzt worden war. Danach hatte der versierte Jurist in der Privatwirtschaft gearbeitet, war aber auch hier vor den Nachstellungen der Nationalsozialisten nicht sicher gewesen. 1940 hatte er sich für mehrere Wochen im Polizeigefängnis am Berliner Alexanderplatz in Schutzhaft, anschließend sieben Monate in Haft im Konzentrationslager Sachsenhausen befunden. Nach dem Zusammenbruch der NS-Herrschaft war er von seinem Parteigenossen Karl Steinhoff als Landrat nach Eberswalde in die Mark Brandenburg geholt worden ${ }^{15}$.

Schmidts Vorschlag traf in der Fürther SPD auf Skepsis. Viele hatten Bornkessel als einen Mann von robuster Durchsetzungskraft in Erinnerung behalten, der sich auch von der eigenen Partei nicht gerne Zügel anlegen ließ. Er sprach seine Genossen mit Sie und nicht, wie es in der SPD damals üblich war, mit Du an. Trotz dieser Vorbehalte stimmte die SPD zu, weil kein anderer Kandidat zu finden war und Bornkessel als hervorragender Verwaltungsfachmann galt. Die ersten Kontakte zwischen Eberswalde und Fürth wurden noch im November 1945 geknüpft. Schmidt schrieb an Bornkessel: „... ich bin zur Zeit in großer Sorge um Ihr Wohlergehen, weil von Ihnen seit Januar dieses Jahres keine Nachricht mehr in Fürth eingelaufen ist ... Sie werden mich verstehen, wenn ich Sie bitte, wenn irgend möglich, mir Nachricht zu geben, ob und wann ich damit rechnen kann, daß Sie sich uns wieder in irgendeiner Form zur Verfügung stellen. Ich kann natürlich heute keine Versprechungen machen für die künftige Leitung der Stadt."16 Bornkessel war sofort bereit, nach Fürth zu kommen. "Ihrer Aufforderung bin ich bereit ohne Zögern Folge zu leisten und werde mich beeilen, mich hier herauszulösen“, schrieb er an den Parteifreund. Bereits Ende November waren in Fürth die Weichen gestellt, die überwiegende Mehrheit des Beratenden Ausschusses akzeptierte Bornkessel als Oberbürgermeister, wie Schmidt sofort nach

13 Det. Fürth, Hist. Rep. für November 1945, in: NA, RG 260, 9/96-3/9-10.

14 Vgl. das Kapitel über den Aufbau der politischen Parteien (S. 173).

15 Vgl. Mauersberg, Wirtschaft und Gesellschaft, S. $173 \mathrm{f}$.

16 Am 19. März 1946 wurde Bornkessel zum neuen Oberbürgermeister bestellt. Alle Nachweise im umfangreichen Briefwechsel zwischen Bornkessel und Schmidt aus den Monaten November 1945 bis Februar 1946, in: Stadtverwaltung Fürth, Personalakte Bornkessel. 
Eberswalde kabelte. Bornkessel sagte umgehend zu: „Wenn ich Ihrem Ruf Folge leiste, so im Vertrauen auf die treue Mitarbeit der altbewährten Freunde und Genossen aus der Partei und Gewerkschaft ... Möchte es vor allem gelingen, die deutschen Arbeiter politisch zu einigen und zusammenzuschließen zu einem unüberwindlichen Block.“

Die Entscheidung war damit gefallen, doch alle Beteiligten hatten wohl die Schwierigkeiten unterschätzt, die damals einer Ủbersiedlung aus der sowjetischen Zone entgegenstanden. Karl Steinhoff, der Ministerpräsident von Brandenburg, ließ seinen Landrat zwar ungern gehen, sicherte ihm aber zu, ihn „mit heiler Haut aus der sowjetischen Besatzungszone hinauszubringen“. Wie umständlich die Prozeduren waren, zeigte ein Brief, den Schmidt dem designierten Oberbürgermeister kurz vor Weihnachten schrieb: „Nach langen Verhandlungen mit der Militärregierung in Fürth, dem Regierungspräsidenten und der Militärregierung in Ansbach haben wir die Genehmigung erhalten, Sie am 27. 12. mit einem Fahrzeug der Militärregierung abholen zu lassen ... die Fahrt wird nicht direkt erfolgen, denn auch die Militärregierung muß ihre Wagen auf vorgeschriebenen Wegen, und zwar über Frankfurt-Kassel-Berlin und zurück laufen lassen.“ Die Bemühungen blieben aber zunächst erfolglos. Anfang Januar wartete Bornkessel noch immer auf den angekündigten Wagen: „Ich habe nun gestern und heute auch meinerseits Schritte unternommen, um meine Ausreise zu beschleunigen. Die Dienststelle des Bez.-Bürgermeisters verwies mich an das USA-Hauptquartier in Berlin-Zehlendorf-Telefunkenhaus, wo ein Leutnant Jones diese Fragen bearbeitet. Ich wurde belehrt, daß nur auf Grund eines Ausweises einer amerikan. Dienststelle in Fürth od. Ansbach eine Genehmigung erteilt werden könne. Für den Fall, (daß) der angekündigte Wagen noch käme, würde er sicher ein entsprechendes Dokument mitbringen. Mit diesem möchte ich dann wieder kommen, die Erledigung erfolge dann sehr schnell. Außerdem habe ich mich in einem Reisebüro beraten lassen. Auf Grund Ihres Ausweises vom 30. Nov. könnte ich eine Fahrkarte nach Thüringen erhalten. Ich müßte dann selbst sehen, wie ich hinüber komme. Angeblich ist damit ein Überlandmarsch von ca. $10 \mathrm{~km}$ über bergiges Gelände verbunden, den ich mir zu dieser Jahreszeit nur mit leichtestem Gepäck zumuten möchte. U. U. käme ich dann etwas zerzaust in Fürth an! Hiervon abgesehen möchte ich es besonders im Hinblick auf Ihre Besprechungen bei den Dienststellen der Militärregierung in Fürth und Ansbach tunlichst vermeiden, mich als desig. komm. Oberbürgermeister mit einer Handlung einzuführen, die gegen die Vorschriften der Alliierten Militärbehörde verstößt.“

Immer wieder mußte Bornkessel seinen Parteifreund Schmidt vertrösten, einmal fehlte dieses Papier, ein andermal jenes: „Es kostet entsetzlich viel Nerven, überall unter Hunderten anstehen zu müssen, um dann nach Stunden gnädigst einen Fragebogen zu bekommen. Niemand kann wirklich zuverlässigen Bescheid geben und alles hängt vom Zufall ab.“ Anfang Februar 1946 schien es dann doch endlich so weit zu sein: „In strömendem Regen waren Hunderte von Flüchtlingen usw. nach dem Sammellager in Berlin-Moabit geeilt, zum Teil mit zentnerschweren Lasten; schon war die Abfertigung in vollem Gange, viele hatten bereits die Marschverpflegung empfangen da plötzlich während des Aufrufs der Namen - ,alles einstellen: Transport geht nicht Gepäck wieder abladen!" - Schluß - aus. Alles ist zunächst fassungslos, und dann gehen alle Maschinen wieder rückwärts." Schließlich erhielt Bornkessel aber doch die Erlaubnis, einen Zug der Alliierten nach Frankfurt/Main zu benützen, und am 25. Fe- 
bruar traf im Fürther Rathaus endlich die Botschaft ein: „Ankomme Fuerth heute Mitternacht.“17

Neben der Besetzung der Posten des Regierungspräsidenten und der Bürgermeister der beiden Städte Ansbach und Fürth, kam der Bestellung neuer Landräte in beiden Kreisen besondere Bedeutung zu. In Ansbach war die Suche der amerikanischen Militärregierungsoffiziere nach einem neuen Landrat zunächst erfolglos. Fast alle Repräsentanten der nationalkonservativen ländlichen Honoratiorenschaft hatten sich während des Dritten Reiches - obwohl keineswegs immer regimefromm - doch wenigstens nominell mit dem Nationalsozialismus eingelassen. Relativ unbelastet und gut qualifiziert erschien den Amerikanern schließlich der ehemalige Ansbacher Oberbürgermeister Wilhelm Borkholder, der - wie Schwiening - der NSDAP angehört hatte. Doch Borkholder, fast 60 Jahre alt, verstarb schon zwei Monate später ${ }^{18}$. Ihm folgte am 4. Juli Richard Neff (Jg. 1892), ein aus Oberbayern stammender Einser-Jurist, der in einigen Berliner Reichsministerien eine vielversprechende Beamtenlaufbahn begonnen und zuletzt im Range eines Ministerialrats gearbeitet hatte ${ }^{19}$ - ein „Auswärtiger" also, dessen Ernennung in Ansbach kaum weniger Aufsehen erregte als die Wahl Körners oder die Einsetzung Schregles. Neff, der sich im Juli 1945 auf dem Weg von Berlin nach München befand, verdankte seine Ernennung dem Zufall. Seine Frau berichtet:

„Wir waren Ende Juni 1945 auf dem Weg nach München, wo sich mein Mann den deutschen Behörden zur Mitarbeit zur Verfügung stellen wollte. Unser Transportmittel war, wie damals üblich, ein Lastauto. Es war ein sogenannter Gemüselaster, der mit Genehmigung amerikanischer Dienststellen in Bayern Gemüse einkaufen sollte, um es in benachteiligteren Gegenden zu verteilen. Auf dem Hinweg war das Auto leer, also konnte der Fahrer Passagiere mitnehmen, und zwar bis Nürnberg. Dort hatten alle auszusteigen, inmitten der Trümmer dieser Stadt. Aus Entgegenkommen erklärte sich der Fahrer bereit, uns noch ein Stückchen weiter mitzunehmen. Am Ende der nächsten Stadt, die wir durchfuhren, hatten auch wir auszusteigen. Es war in Ansbach. Bei einem kurzen Rundgang durch die kleine Stadt fielen uns Plakate auf, die besagten, daß sich alle ehemaligen Beamten unverzüglich bei der Militärregierung zu melden hätten. Das bezog sich auch auf meinen Mann. Die Militärregierung befand sich im Stadtzentrum. Das Hauptportal wurde von Gl's bewacht, die meinem Mann erklärten, er dürfe diesen Haupteingang nicht benutzen - er hätte wie alle anderen Deutschen nur Zugang über die Hintertreppe. Von dort aus wurde er zu einem jungen Leutnant gebracht, der, wie sich später herausstellte, ein Soziologieprofessor aus Connecticut war. Nach einigem Hin und Her hatte mein Mann einen Fragebogen auszufüllen, aus dem u.a. hervorging, daß er ein sogenannter Einser-Jurist und erfahrener Verwaltungsbeamter war und antinationalsozialistisch eingestellt. Der Chef der Ansbacher Militärregierung und der Chef der Militärregierung von Ober- und Mittelfranken kamen hinzu, und mein Mann wurde gefragt, ob er nicht Landrat vom Landkreis Ans-

17 Ebenda und schriftliche Mitteilung von Alfred Schmidt vom 10. November 1984.

18 Vgl. LR Ansbach an RegPräs, 3. Juli 1945, in: LRA Ansbach, EAP 01-016; vgl. auch BayHStA, MInn 80389.

$19 \mathrm{Zu}$ Neff vgl. LRA Ansbach, EAP 01-015 und Amts- und Mitteilungsblatt des Landkreises Ansbach, 20. Februar 1952, S.3. 
bach werden wolle. Er erbat sich 24 Stunden Bedenkzeit, denn seine ursprüngliche Absicht war ja, nach München zu gehen ... Schließlich sagte mein Mann zu, und so wurde er in den ersten Julitagen 1945 als Landrat eingesetzt." 20

Im Kreis Fürth dagegen war die Besetzung des Landratsamtes schon zwei Monate zuvor gleichsam routinemäßig gelaufen, so wie die Offiziere der Militärregierung es in den Ausbildungszentren vorgesehen und geübt hatten. Captain Cofer stieß im Gespräch mit Oberbürgermeister Schwiening, einigen höheren Beamten der Stadtverwaltung und je einem Vertreter der beiden Kirchen auf die einhellige Empfehlung zugunsten von Otto Graf (Jg. 1894). Auch Cofer selbst, der schnell erfahren hatte, daß Graf an der kampflosen Übergabe Fürths mitgewirkt hatte, fand Gefallen an dem Wirtschaftsexperten. Am 5. Mai wurde Graf als neuer Landrat bestellt ${ }^{21}$. Die Räume in der Amalienstraße 4 wurden dem ehrgeizigen Mann aber bald zu eng, Graf hatte anderes im Sinn: „Er hatte zu viele andere Interessen und widmete dem Landkreis nicht genügend Aufmerksamkeit“, urteilte die Militärregierung ${ }^{22}$. Anfang Juni löste ihn deshalb der Spiel- und Metallwarenfabrikant Friedrich Hörndlein (Jg. 1899) aus Nürnberg ab. Auch dies war eine unkonventionelle Entscheidung, denn Hörndlein verfügte über keinerlei Verwaltungserfahrung und war auch politisch bisher nicht hervorgetreten. Auf ihn waren die Amerikaner von Landarzt Dr. Landvogt aus Roßtal aufmerksam gemacht worden, der sich bei Kriegsende für eine kampflose Übergabe Roßtals eingesetzt und damit das Vertrauen einiger Offiziere der Militärregierung erworben hatte ${ }^{23}$

Im Mai 1945 waren trotz zum Teil erheblicher Schwierigkeiten die Spitzenpositionen in der Verwaltung der Regierungsbezirks-, Landkreis- und Stadtebene mit neuen unbelasteten Leuten besetzt. Das war keine mittelfränkische Spezialität, die amerikanische Militärregierung drängte überall - mit Erfolg - auf ein schnelles Revirement in der deutschen Verwaltung. Im oberfränkischen Kulmbach war am 7. Mai 1945 der frühere SPD-Abgeordnete im bayerischen Landtag, Georg Hagen, der sich im Dritten Reich als Versicherungsagent durchgeschlagen hatte, als neuer Bürgermeister vereidigt worden. In Bamberg hatte die Militärregierung im April 1945 den Oberbürgermeister aus der Weimarer Zeit, Luitpold Weegmann, wieder in sein Amt geholt. Und in München war am 8. Mai 1945 Karl Scharnagl in das Rathaus zurückgekehrt, das er schon vor 1933 geleitet hatte ${ }^{24}$. Die Neubildung der Landesverwaltungen ließ sich in so kurzer Zeit nicht durchführen, da ja zunächst auch die territoriale Gestalt der einzelnen Länder noch kaum zu erkennen war. In Bayern, das territorial unversehrt geblieben war, amtierte mit Fritz Schäffer, dem früheren Führer der Bayerischen Volkspartei, der den Amerikanern von Kardinal Faulhaber vorgeschlagen worden war, bereits Ende Mai 1945 wieder ein Ministerpräsident. Das aus Teilen der ehemaligen Länder Würt-

20 Schriftliche Mitteilung von Elisabet Neff vom 6. Juli 1981; vgl. auch Annual Hist. Rep., Det. Ansbach, 1 September 1946, in: NA, RG 260, 10/80-3/6

21 Graf war Mitglied der katholischen Studentenverbindung „Normannia“. 1924 trat er als Regierungsassessor in den Staatsdienst ein, zwischen 1936 und 1945 leitete er die nordbayerische Außenstelle des Reichswirtschaftsministeriums in Fürth. Vgl. Fürther Nachrichten vom 28. März 1953 und Annual Hist. Rep., Det. Fürth, 20. Juni 1946, in: NA, RG 260, 10/81-1/5.

22 Annual Hist. Rep., Det. Fürth, 20. Juni 1946, in: NA, RG 260, 10/81-1/5.

23 Schriftliche Mitteilungen von Georgine Hömdlein vom 26. Oktober 1981 und Michael Wiesinger vom 20. September 1981 und 19. Oktober 1981

${ }^{24} \mathrm{Zu}$ Hagen vgl. Wilhelm Lederer, Dokumentation 1945. Kulmbach vor und nach der Stunde Null, Kulmbach 1971, S. 153 ff. Zu Weegmann vgl. Stadtarchiv Bamberg, B.S. Nr. 483 sowie Bamberger Volksblatt vom 29. August 1966. Zu Scharnagl vgl. u.a. Niethammer, Entnazifizierung, S. 166. 
temberg und Baden neu gebildete Land Württemberg-Baden erhielt am 2. Oktober 1945 eine Regierung mit Reinhold Maier an der Spitze. Karl Geiler, Regierungschef des neu geschaffenen Landes „Groß-Hessen“, übernahm sein Amt erst vierzehn Tage später ${ }^{25}$.

Zugleich mit der Neubesetzung der Spitzenpositionen in der mittleren und höheren Verwaltung begannen die Offiziere der Besatzungsmacht in den ländlichen $\mathrm{Ge}$ meinden die politisch belasteten Gemeindeoberhäupter auszutauschen. Im Landkreis Fürth hatte diese Aufgabe 2nd Lt. Milton Solomon übernommen, der schon ab Mai zusammen mit Edward Kiczmamochski - einem bei der US-Armee angestellten polnischen Fremdarbeiter - und einem Dolmetscher mit dem Jeep über Land fuhr ${ }^{26}$. In Roßtal, einem Marktflecken südlich von Fürth, machte das kleine Team bald Station. Solomon sah sich auf dem Marktplatz etwas um, ließ den Dolmetscher einige Bürger befragen und erhielt dabei den Hinweis, daß der Bauer Michael Wiesinger das Zeug zum Bürgermeister habe. Außerdem wurde er noch auf einige fähige und integere Kommunisten aufmerksam gemacht, die er zusammen mit Wiesinger sofort in das Rathaus bestellte. Dort erhielt jeder einen Fragebogen, den er auszufüllen und sofort wieder im Rathaus abzugeben hatte. „Einige Tage später“, so berichtete Wiesinger, „um 11.00 Uhr (ich befand mich in meinem Pferdestall) kamen 4 Offiziere, darunter ein deutschsprachiger, zu mir und holten mich mit ihrem Auto ab. Ich durfte nicht mehr in mein Haus, mußte wie ich war - in Arbeitskleidung - mitfahren, sie sagten mir auch nicht warum und wohin. Meine Familie und ich waren sehr erregt, weil man ja nicht wußte, was sie mit mir vorhatten. Die Fahrt ging zum Rathaus. Ein Offizier sprach dann mit dem Dolmetscher, dieser sagte dann zum anwesenden Bürgermeister Flachenecker, Du bist ab sofort nicht mehr Bürgermeister, Du kannst heimgehen. Drauf sprach mich der Dolmetscher an und sagte zu mir, da ist jetzt Dein Platz, ab jetzt bist Du Bürgermeister in Roßtal."27

Bereits nach drei Monaten konnte Solomon seiner vorgesetzten Stelle melden, daß von den 34 Bürgermeistern aus der ,alten Zeit“ keiner mehr im Amt sei ${ }^{28}$. Zum selben Zeitpunkt, im Juli 1945, waren von den 82 Bürgermeistern des Landkreises Ansbach erst „47 auf Anordnung der Militärregierung wegen ihrer Parteizugehörigkeit bzw. politischen Belastung ihres Amtes enthoben“ worden ${ }^{29}$. Daß in Ansbach noch immer fast die Hälfte der alten Bürgermeister amtierte, hatte seinen Grund darin, daß im Landkreis erst seit Anfang Juli eine eigene Abteilung der Militärregierung stationiert war und das Ansbacher Umland bis dahin meist vom ohnehin ausgelasteten Regierungsbezirksdetachment mitverwaltet werden mußte, das den Belangen des Landkreises nicht die nötige Aufmerksamkeit schenken konnte ${ }^{30}$. Der dann bald eintreffenden Militärregierungseinheit unter Col. Whitaker gelang es aber schnell, die anfänglichen Versäumnisse wettzumachen, und schon am 3. Oktober 1945 erreichte den

25 Zur Neubildung der Landesverwaltungen vgl. Theodor Eschenburg, Jahre der Besatzung 1945-1949, Stuttgart 1983, S. 77-84.

26 Vgl. Berichte des Det. Fürth über Landkreisinspektionsreisen vom 19., 22. und 26. Juni 1945, in: LRA Fürth, EAP 070/1.

27 Schriftliche Mitteilungen von Michael Wiesinger vom 1. und 20. September 1981.

28 Vgl. LR Fürth an RegPräs, 5. August 1945, in: StA Nürmberg, LRA Fürth (1962), Nr. 40/1.

29 LRA Ansbach an RegPräs, 3. Juli 1945, in: LRA Ansbach, EAP 01-016.

$30 \mathrm{Vgl}$. dazu das Kapitel über den Einmarsch der amerikanischen Truppen (S.65 f.). 
Regierungspräsidenten auch aus dem Landkreis Ansbach die Meldung: „Die politische Bereinigung bei den Bürgermeistern ist nunmehr durchgeführt. ${ }^{\text {"31 }}$

Die Militärregierungen hatten gründliche Arbeit geleistet und sich dabei strikt an ihre Anweisung gehalten, keinen Bürgermeister oder Landrat aus der NS-Zeit im Amt zu belassen. Dieser völlige Bruch der personellen Kontinuität in den Rathäusern war wahrhaft revolutionär und bedeutete einen tieferen Einschnitt als die Maßnahmen der Nationalsozialisten nach der Machtergreifung, die es nicht wenigen deutschnationalen und parteilosen Bürgermeistern ermöglicht hatten, sich zu arrangieren und im Amt zu bleiben. Die Mehrheit der Bevölkerung hat dieses umfassende Revirement ohne Protest hingenommen. Mochte mancher Bürgermeister der NS-Zeit in seiner Gemeinde auch weiterhin als anständig und integer angesehen werden, man verstand doch offenbar, daß die alten Amtsträger zu kompromittiert waren, vor allem für eine glaubwürdige Vertretung der Interessen der Bevölkerung gegenüber der Militärregierung. Lediglich in einigen wenigen Dörfern und Kleinstädten kam es zu halbherzigen Protesten. Hier waren den pauschalen Maßnahmen der Amerikaner Bürgermeister zum Opfer gefallen, die eher zu den Gegnern des Nationalsozialismus zu rechnen waren als zu seinen Parteigängern. Einer davon war der Bürgermeister der 220-Seelen-Gemeinde Horbach im Landkreis Fürth, der sein Amt bereits seit 1929 ausübte. 1933 der NSDAP beigetreten, war er schon kurz darauf in Konflikt mit der örtlichen Parteileitung geraten, weil er sich als Vorstand der Milchgenossenschaft mit einem „Alten Kämpfer" angelegt hatte, der für das Fahren der Milch das Doppelte des üblichen Fahrgeldes verlangt hatte ${ }^{32}$. Dem Bürgermeister war daraufhin die Einweisung nach Dachau angedroht worden. Später hatte er sich trotz mehrmaliger Aufforderungen der Partei geweigert, sein Amt als Kirchenvorsteher niederzulegen und sich schließlich auch den Weisungen eines SS-Hauptsturmführers widersetzt, in Horbach Panzersperren zu errichten.

Auch der abgesetzte Bürgermeister von Zirndorf war alles andere als ein überzeugter $\mathrm{Pg}$ gewesen, wie auch sein Nachfolger und der Ortsgeistliche bestätigten. Der Ortspfarrer bescheinigte ihm: „Er trat im Kirchenkampf unerschrocken für die Bekennende Kirche ein und tat, was in seinen Kräften stand, um die mancherlei Schwierigkeiten von der NSDAP zu beheben ... Ihm verdanken wir es, daß wir in unserem kirchlichen Leben vor anderen Gemeinden von den Übergriffen fanatischer Gegner unbehelligt blieben ...“ Besonders hoch rechnete der Pfarrer dem Bürgermeister an, daß er Zirndorf kampflos an die Amerikaner übergeben hatte: „Ich war selber Zeuge in dem entscheidenden Augenblick, da er auf die Gefahr hin und trotz der wiederholten Drohungen, daß er an den Galgen gehängt werde, bedingungslos kapitulierte. “33

In Roßtal hatte 2nd Lt. Milton Solomon doppeltes Glück. Er fand sofort Ersatz für den alten Bürgermeister, und Wiesinger, der in Gummistiefeln und Arbeitskleidung zum Bürgermeister berufen worden war, erwies sich als tüchtiger Mann, der schon bald großes Ansehen in seiner Gemeinde genoß. Der gebürtige Schwabacher stammte aus kleinen Verhältnissen und hatte bereits im Kindesalter hart arbeiten müssen. Nach seiner Heirat (1927) übernahm er den Hof seiner Frau und machte ihn mit viel

31 In: LRA Ansbach, EAP 01-016.

32 Alt-Bg Horbach an LR Fürth, 10. Oktober 1945, in: LRA Fürth, EAP 027.

33 Pfarrer von Zirndorf an LR Fürth, 30. Mai 1945, in: Ebenda. 
Fleiß zum größten landwirtschaftlichen Betrieb in Roßtal. Als Bürgermeister wie als Landwirt hielt er sich vor allem an eine Devise: Arbeiten, arbeiten und nochmals arbeiten. Wie geschaffen für außergewöhnliche Zeiten, bewies er beträchtliche Findigkeit bei Kompensationsgeschäften und zögerte auch nicht, in die eigene Tasche zu greifen, wenn Not am Mann war. Damals legte er wohl den Grundstein zur Ära Wiesinger in Roßtal, die erst 1972 zu Ende ging ${ }^{34}$.

Solomons Glücksgriff mit Wiesinger konnte die Offiziere der Militärregierung aber nicht darüber hinwegtäuschen, daß es ihnen an ausreichenden Sprach-, Orts- und Milieukenntnissen und auch an genügend eigenem Personal fehlte, um die Vorschläge von NS-Gegnern und Pfarrern sorgfältig zu prüfen. Wie sehr sie damit Mißgriffe riskierten oder in Gefahr gerieten, von rivalisierenden Dorfgruppen mißbraucht zu werden, zeigte sich besonders drastisch in Seukendorf, wo sich die Auswahl eines neuen Gemeindeoberhaupts zu einer aufsehenerregenden Provinzposse entwickelte, in der sich Militärregierungsoffiziere und CIC-Angehörige, ein Landesbischof, ein Oberkirchenrat und der Ortspfarrer, ein Bürgermeister und ein Landrat in den Hauptrollen abwechselten.

Seukendorf ${ }^{35}$, etwa zehn Kilometer westlich von Fürth gelegen, zählte 1945 etwa 350 Einwohner. Der größte Teil der fast durchweg evangelischen Bevölkerung lebte von der Landwirtschaft, die wenigen Arbeiter gingen in Nürnberg, Fürth und Zirndorf ihrem Broterwerb nach. Als sich die Amerikaner im April 1945 dem Dorf näherten, setzte sich Bürgermeister Leonhard Croner mit den amerikanischen Einheiten in Verbindung und ließ weiße Fahnen hissen. Croner führte sein Amt noch bis zum 1. Juni weiter, dann mußte er die Geschäfte auf Weisung der Militärregierung an Josef Willner übergeben, einen ehemaligen Feldwebel und kleinen „Sachler“, wie man im Ort sagte. Willner, ein notorischer Querulant, hatte fast das ganze Dorf gegen sich. In den zurückliegenden Jahren hatte er sich stets mit den Bürgermeistern angelegt mit dem Ziel, selbst Bürgermeister zu werden. In der Weimarer Zeit war der sehr angesehene Bürgermeister Blödel, zugleich Abgeordneter im bayerischen Landtag, wegen Willners Quertreibereien nicht weniger als dreimal zurückgetreten, dann aber auf Zureden der Seukendorfer immer wieder im Amt verblieben. Daß Willner sein Lebensziel doch noch erreichte, verdankte er einzig dem evangelischen Pfarrer, der ihn der amerikanischen Militärregierung empfohlen hatte. Der Pfarrer, der nach Seukendorf strafversetzt worden war, war im Ort nicht allzu beliebt; man mißtraute ihm. Es half seiner Glaubwürdigkeit auch wenig, daß er der Bekennenden Kirche angehört und nicht selten von der Kanzel herab gegen die NSDAP gewettert hatte. Die Seukendorfer, die ihre Ruhe haben wollten und fürchteten, der politisierende Pfarrer könne mit seinen „Hetzreden“ dem ganzen Dorf Schwierigkeiten bereiten, waren dadurch eher irritiert. Umso mehr schloß sich der im Dorf isolierte Pfarrer Willner an. Er hielt ihn für einen entschiedenen NS-Gegner, weil Willner kurz nach der Machtergreifung der National-

$34 \mathrm{Zu}$ den biographischen Daten vgl. schriftliche Mitteilung von Michael Wiesinger vom 24. Mai 1982.

35 Alle Nachweise in: LRA Fürth, EAP 027: Gemeindeangelegenheiten Seukendorf. Mündliche Mitteilungen von Kaspar und Adolf Ultsch vom 21. Januar 1982 sowie Kurzprot. der Vollsitzungen des Evangelisch-Lutherischen Landeskirchenrates vom 15./16. April, 20./22. Mai, 12./13. Juni und 25./26. Juli 1946, in: LKA Nürnberg, Bestand: Ev.-Luth. Landeskirchenrat, Niederschriften über Haus- und Vollsitzungen 1940, 1945 und 1946. Vgl. auch Visitationsbericht von Dekan Fürst vom 23. Mai 1943, in: Ebenda, Bestand: Bay. Dekanat Fürth, Nr. 113 a. 
sozialisten wegen seines Querulantentums aus der NSDAP ausgeschlossen worden war, deren Ortsgruppe er 1932 mitaufgebaut hatte.

Diesen verwickelten Dorfgeschichten gegenüber stand die Militärregierung auf verlorenem Posten. Sie wußte weder von Willners früherer Parteimitgliedschaft, noch war ihr bekannt, daß der neue Bürgermeister in den Kriegsjahren als Chef der örtlichen Landwacht gebieterisch durch das Dorf stolziert war und jeden schärfstens verwarnt hatte, der einem Fremdarbeiter ein Stück Brot zusteckte. Er halte die Polen „wie Hunde“, sagte man damals in Seukendorf. Die amerikanischen Offiziere folgten der Empfehlung des Pfarrers, der durch seine Nonkonformität während der NS-Zeit als besonders vertrauenswürdig galt, und gerieten so in den Seukendorfer Bürgermeisterkrieg. Willner wußte sich auf seine Weise bei der Militärregierung beliebt zu machen. Er wartete mit selbstgebranntem Schnaps auf, außerdem mit drei Töchtern in heiratsfähigem Alter, die es den Amerikanern offenbar besonders angetan hatten.

Recht glücklich wurde Willner auf seinem Posten freilich nicht, denn die Einwohner Seukendorfs wollten sich seinem Feldwebelton nicht unterordnen. Sein eigentlicher Gegenspieler war die graue Eminenz des Dorfes, der Landmaschinenschlosser und -händler Kaspar Ultsch. Als Mitglied des örtlichen Kirchenvorstandes aktiv in der evangelischen Kirche tätig, hatte Ultsch sich mit den Nationalsozialisten nie recht anfreunden können. Er war aber schließlich doch der Partei beigetreten, weil man ihm gedroht hatte, seine Schlosserei andernfalls nicht mehr mit Eisen zu beliefern. Seine Wohnung war während der NS-Zeit so etwas wie ein „Dorfparlament“, wo sich die Bauern in unregelmäßigen Abständen nach Feierabend trafen und die Belange des Dorfes besprachen. Ultsch und Willner kannten einander von Kindesbeinen an, waren sich aber „spinnefeind“, denn ein Streit um ein Fahrtrecht belastete schon seit Generationen das Verhältnis der beiden Familien.

Nachdem einige Versuche, Willner zum freiwilligen Rücktritt zu bewegen, fehlgeschlagen waren, gaben seine Gegner ihre Zurückhaltung auf und gingen an die Ö́fentlichkeit. So leicht war Willner aber nicht beizukommen. Er drehte den Spieß um, gab sich als überzeugter Demokrat und stellte seine Gegner, allen voran Ultsch, als unbelehrbare Pgs hin. Damit hätte er vielleicht erneut die Oberhand behalten, wenn sich nicht zwei DP's bei der Militärregierung gemeldet hätten, die schwere Beschuldigungen gegen Willner vorbrachten: „Willner Josef war Führer der Landwacht und des Volkssturms und hat Polen sowie Franzosen auf das Niederträchtigste behandelt, sie zum Teil mit dem Gummiknüppel geschlagen - ohne Ursache, lediglich weil sie Ausländer waren. Des öfteren hat er sie auch bei dem Ortsgruppenleiter ... in Burgfarrnbach denunziert. Die Polen waren über das Benehmen Willners so erbost, daß sie nach dem Einrücken der Amerikaner das Haus $W$ illners anzünden wollten. Es ist ihnen unverständlich, daß Willner nun zum Bürgermeister ernannt worden ist. Willner soll Mitbegründer der Ortsgruppe der NSDAP vor 1933 in Seukendorf gewesen sein.“ Als Willner mit diesen Vorwürfen konfrontiert wurde, wand er sich zunächst, gab dann aber kleinlaut zu, daß er als Mitglied der Landwacht tatsächlich Schwierigkeiten mit den Fremdarbeitern gehabt hatte. Damals sei ihm von seinem Vorgesetzten geraten worden, „die muß man nauf hauen“.

CIC zögerte nicht lange: „Die Entlassung von Willner wird von dieser Stelle dringend befürwortet.“ Die Militärregierung beschäftigte sich nun erstmals näher mit den Ereignissen in Seukendorf und zog von den verschiedensten Stellen Informationen 
ein, u.a. auch von Ultsch, der offenbar schnell ihr Vertrauen gewann. Den amerikanischen Offizieren gingen nun endlich die Augen auf. Nach einer längeren Unterredung mit Ultsch schrieb ein Offizier der Militärregierung einige Zeilen auf ein Stück Papier und beauftragte Ultsch, den Zettel umgehend Landrat Hörndlein zu überbringen. Auf dem Zettel stand nur: „Suchen Sie einen anderen Bürgermeister für Seukendorf.“ Ultsch sollte dem Landrat bei der Suche nach dem neuen Gemeindeoberhaupt behilflich sein. Willner wurde kurz darauf seines Postens enthoben.

Diese Entscheidung traf das Dorfparlament von Seukendorf, das auch nach dem Ende der NS-Herrschaft das eigentliche Zentrum der örtlichen Politik blieb, nicht unvorbereitet. In der Wohnung von Ultsch hatte man bereits seit längerem über einen Nachfolger für Willner nachgedacht und war dabei zu dem Ergebnis gekommen, einen Sozialdemokraten an die Spitze der Gemeinde zu stellen, schienen doch die Zeichen eindeutig auf „rot“ zu stehen. Auf vielen wichtigen Posten in der Staatsregierung in München und im Landratsamt in Fürth saßen Sozialdemokraten - da konnte es nicht schaden, einen sozialdemokratischen Bürgermeister zu haben, dachten die konservativen Bauern in Seukendorf, die stets ein distanziertes Verhältnis zur staatlichen Obrigkeit gehabt hatten, der man sich beugen mußte, aber auch Vorteile abluchsen konnte, wenn man es nur geschickt genug anstellte. Das Umdenken auf die neue Zeit fiel den Bauern um so leichter, als sie den Sozialdemokraten, der für das Amt des Bürgermeisters in Frage kam, seit langem als vernünftigen Mann kannten. Es war der 47jährige Johann Burger, der sich vom Hilfsarbeiter zum Gärtnereibesitzer hochgearbeitet hatte.

Damit erhielt die Affäre in Seukendorf zusätzlichen Zündstoff. Zwischen Burger und Willner bestand nämlich eine langjährige Feindschaft, die darauf zurückging, daß Willner dem Sozialdemokraten während der NS-Zeit beträchtliche Schwierigkeiten bereitet hatte. In den folgenden Jahren ging es hoch her in Seukendorf, denn Willner konnte sich von dem Gedanken, wieder Bürgermeister zu werden, nicht losreißen. Er „ließ ... nicht nach, dem Bürgermeister und Gemeinderat das Leben möglichst schwer zu machen“, beklagte sich der Gemeinderat beim Landrat, „getreu seinem Ausspruch ... er werde dafür sorgen, daß der neue Bürgermeister nicht länger als vier Wochen im Amt bleibe.“ Daß der Störenfried nicht besänftigt werden konnte, war wohl auch der Militärregierung zuzuschreiben, die Willner viel zu lange die Stange gehalten und deshalb in Seukendorf stark an Autorität eingebüßt hatte.

Die Auseinandersetzungen verschärften sich sogar noch. Der Pfarrer ergriff von der Kanzel herab Partei für seinen Intimus und prangerte das „rote Günstlings- und Gewaltregiment" Burgers an. Daraufhin schaltete sich der von Ultsch geleitete Kirchenvorstand ein und drängte auf die Versetzung des Pfarrers, der seine kirchlichen Kompetenzen weit überschritten hatte: „Die Verhältnisse in Seukendorf gestatten keine andere Lösung der Frage, da alle Versuche zu einer friedlichen Lösung fehlgeschlagen sind.“ Anfang Mai 1946 drohten erst Burger, dann der stellvertretende Bürgermeister und schließlich der ganze Gemeinderat ihre Ämter niederzulegen. Eine Veränderung der Lage in Seukendorf sei nicht zu erwarten, so hieß es im Protokoll der Gemeinderatssitzung vom 7. Mai 1946, ehe „nicht eine gründliche Säuberung erfolgt ist. Der Kampf des als alten Nazi und unverbesserlichen Stänkerer bekannten Josef Willner richtet sich nicht gegen eine einzelne Person, sondern sein einziges Ziel ist und bleibt die Stelle des Bürgermeisters, und jeder, der ihm dabei im Weg ist, wird von ihm be- 
kämpft, und zwar mit allen, auch den gemeinsten Mitteln. Trotzdem die Gemeinde ihn einmütig ablehnt, sowohl die Antifaschisten wie auch seine Gesinnungsgenossen von früher, die Nazis, wühlt er unentwegt weiter und hetzt gegen jeden, der ihm im Wege steht. In dieser Erkenntnis sieht sich kein Mann des Gemeinderats in der Lage, sein Amt weiterzuführen.“

Nachdem der Kirchenvorstand ein zweites Mal die sofortige Versetzung des Pfarrers gefordert hatte, mußte sich die Kirchenleitung um die Vorkommnisse in Seukendorf kümmern, die mehr und mehr auch das Ansehen der evangelischen Kirche in Mitleidenschaft zu ziehen drohten. Oberkirchenrat Julius Schieder aus Nürnberg begab sich im Frühjahr 1946 persönlich in die Konfliktgemeinde, um nach dem Rechten zu sehen - eine heikle Mission, denn welchen Eindruck würde es in der Öffentlichkeit machen, wenn die evangelische Kirche, die nicht zögerte, einige „braune“ Schafe in den eigenen Reihen rückhaltlos zu decken, ausgerechnet einen mutigen Streiter gegen den Nationalsozialismus zur Ordnung rief? Schieder versuchte deshalb zu schlichten und wies den Pfarrer an, „sich vor allem zu hüten, was auch nur den Anschein erwecken könnte, als wolle er sich in außerkirchliche Angelegenheiten einmischen“. Die Affäre erschien ihm aber doch so brisant, daß er einen ausführlichen Bericht an den Landeskirchenrat in München sandte.

Die Entscheidung über das Schicksal des Pfarrers lag damit in München. Am 23. Mai 1946 wandte sich Landesbischof Meiser an den Landrat in Fürth: „Die von uns geführte Untersuchung ergab nichts, was es uns ermöglichen könnte, Herrn Pfarrer Recker in gesetzmäßiger Weise gegen seinen Willen zu versetzen, zumal er sein Amt bisher ohne Tadel geführt hat.“ Mit so dürren Worten wollte sich der Landrat aber nicht abspeisen lassen. Am 4. Juli 1946 schrieb er an den Evangelisch-Lutherischen Landeskirchenrat in München: „Die Ablehnung der Versetzung des Pfarrers Recker hat in der Gemeinde Seukendorf allgemein größtes Befremden hervorgerufen. - Auch kann ich mir nicht erklären, daß die von der Gemeinde gebrachten Gründe nicht zu einer Versetzung ausreichen sollten. - Ich bitte den Fall nochmals eingehend zu überprüfen. - ... Trifft es zu, daß Recker die neue von der Militärregierung eingesetzte Gemeindeführung von der Kanzel aus bewußt verleumdet, so dürfte das allein schon eine sofortige Versetzung rechtfertigen. - Der Bürgermeister von Seukendorf hat mir in einer Unterredung bei Amt am 3.6.1946 eröffnet, daß der gesamte Gemeinderat zurücktreten wird, falls die Versetzung des Pf. Recker nicht sofort erfolgt. - Es ist bestimmt anzunehmen, daß diese Organe ihr Vorhaben ausführen. - Dadurch entstehen auch mir neuerliche Schwierigkeiten, da es unmöglich ist, in Seukendorf einen neuen Gemeinderat zu bilden, auch ein Bürgermeister könnte nicht mehr gefunden werden. - Ich halte es doch für zweckmäßiger einen mit Recht unbeliebten Pfarrer zu versetzen, als ihn in ständiger Gegnerschaft zu 90 Prozent seiner Gemeindemitglieder zu wissen, denen er ein Berater und Seelsorger sein soll. Der Verbleib des Pfarrers Recker in der Gemeinde ist auch schon um deswillen unfruchtbar, weil der Kirchenbesuch immer mehr zurückgeht und am Ende überhaupt niemand mehr die Gottesdienste besuchen wird."

Nun konnte man kirchlicherseits nicht mehr darauf hoffen, daß allmählich Gras über den Vorfall wachsen würde. Schieder erhielt in der Vollsitzung des EvangelischLutherischen Landeskirchenrats am 12./13. Juni 1946 den Auftrag, „persönlich mit dem Landrat zu verhandeln, damit ein Umzug des Pfarrers Recker vermieden wird“, 
der im Herbst nach vollendetem 65. Lebensjahr in den Ruhestand treten wollte. Die Fronten waren aber so verhärtet, daß Schieder schließlich nichts anderes übrig blieb, als die Versetzung zu befürworten. Willner verlor damit seinen wichtigsten Verbündeten im Ort. In Seukendorf kehrte aber noch lange keine Ruhe ein. Bürgermeister Burger, der in der Gemeindewahl vom Frühjahr 1948 erneut die Mehrheit der Stimmen erringen konnte, mußte sich auch weiterhin gegen Willner zur Wehr setzen, so lange, bis eines Abends einige junge Burschen Willner mit Gewalt zur Dorfräson brachten. Der notorische Querulant ließ sich die Tracht Prügel eine Lehre sein und zog sich ganz aus dem öffentlichen Leben zurück. Nur die Gerichte hatten sich noch eine Weile mit den tätlichen Auseinandersetzungen zu beschäftigen. Burger, der als der geistige Vater der Haberfeldtreiber verdächtigt worden war, überstand aber alle Gerichtsverfahren unbeschadet und blieb bis 1959 Bürgermeister in Seukendorf.

In einigen Orten hatte das gänzlich überforderte kleine Team von 2nd Lt. Milton Solomon, das im Landkreis Fürth seit Mai 1945 mit der Einsetzung von neuen Bürgermeistern beschäftigt war, weder Glück wie im Falle von Wiesinger noch Pech wie im Falle von Willner. Es fand sich nämlich zunächst niemand, der das undankbare Amt des Bürgermeisters übernehmen wollte. So war es beispielsweise in Oberasbach im Landkreis Fürth, wo ein antifaschistischer Ausschuß in das Vakuum stieß, der nach der personellen Zusammensetzung viele Ähnlichkeiten mit den Antifas in den Großstädten mit starker Arbeiterbewegungstradition aufweist ${ }^{36}$. Die aus mehreren Dörfern entstandene Sammelgemeinde Oberasbach am Südrand von Fürth, hatte sich seit dem Ersten Weltkrieg zu einer stattlichen Ortschaft entwickelt, in der sich Arbeiter und Bauern in etwa die Waage hielten. Ausgangspunkt der strukturellen Veränderung der ursprünglichen Bauerngemeinde war eine kleine Siedlergenossenschaft aus Arbeitern der Nürnberger MAN- und Schuckert-Werke, die nach 1918 von der Faber'schen Gutsverwaltung für 65000,- RM ein beträchtliches Stück Ackerfläche nördlich der Bahnlinie Nürnberg-Ansbach erworben hatte. „Diese Siedlerfreunde konnten damals noch nicht ahnen“, so heißt es in der Chronik der Siedlervereinigung, ,welches Werk sie begonnen hatten und wie sich daraus eine Kolonie entwickelte, die mit zu den schönsten Bayerns zählen sollte. Durch die errichtete Satzung sollten den Mitgliedern gesunde und zweckmäßig eingerichtete Kleinwohnungen in eigens erbauten Häusern mit Obst- und Gemüsegärten zu billigen Preisen verschafft werden ..."37 Ende der zwanziger Jahre gehörten bereits 341 Genossen zum Siedlerverein, die Einwohnerschaft von Oberasbach verdoppelte sich zwischen 1925 und 1933 auf 2100 und stieg dann bis 1939 noch einmal um 1000 Personen an. Gemeinschaftsarbeit wurde groß geschrieben: „Es waren echte Idealisten, die hier wirkten. Wie Pilze schossen die Gartenhäuschen aus dem Boden ..." Bald hieß das einstige Bauerndorf in der ganzen Umgebung das „rote Oberasbach“, denn Sozialdemokraten und Kommunisten hatten hier eine starke Domäne. Nach der Machtergreifung der Nationalsozialisten begann für die politisch überwiegend linksstehenden Siedler ein zähes Ringen, das 1941 mit der Auflösung der Genossenschaft endete. Die Spannungen zwischen der ,neuen politischen Richtung“ und den Arbeitern verminderten sich aber bis zum Ende der NS-Zeit

${ }^{36}$ Vgl. v.a. Lutz Niethammer/Ulrich Borsdorf/Peter Brandt (Hrsg.), Arbeiterinitiative 1945. Antifaschistische Ausschüsse und Reorganisation der Arbeiterbewegung in Deutschland, Wuppertal 1976 und Eschenburg, Jahre der Besatzung, S. 105-108.

37 Chronik der Siedlervereinigung Unterasbach, in: Privatbesitz Hans Wild, Oberasbach. 
nicht. Die Linken, meist uk-gestellte Facharbeiter in Rüstungsbetrieben wie MAN, trafen sich nach der Arbeit weiterhin regelmäßig in ihren alten Gastwirtschaften und debattierten über die verbrecherische Kriegspolitik Hitlers. Widerstandsaktionen aber waren ihnen zu riskant. Ihre Stunde schlug erst 1945.

Beim Einmarsch der amerikanischen Truppen war das Rathaus fast verwaist. Bürgermeister Friedrich Landler blieb zwar bis August nominell im Amt, hatte seine Autorität aber längst eingebüßt. In dieser Situation formierte sich die „Antifaschistische Einheitsfront" aus etwa $\mathbf{4 0}$ Sozialdemokraten und Kommunisten, die sich zumeist aus der Siedlergenossenschaft oder von der Arbeit her kannten. Den Vorsitz führte der stellvertretende Leiter des Fürther Arbeitsamtes, Ernst Sehlmacher, ein Sozialdemokrat. Seine rechte Hand und einer der Aktivisten im Komitee war Hans Wild, ein um die Jahrhundertwende geborener Werkzeugmacher, der während der Weimarer Zeit zu den prominentesten Kommunisten im Landkreis Fürth gehört hatte ${ }^{38}$. Sehlmacher und Genossen tagten nach Feierabend in der Wohnung von Wild. Als Ziele für die künftige Gemeindeverwaltung hatten sie sich gesetzt:

„1. Einsetzung eines ebrenamtlichen Bürgermeisters.

2. Schaffung einer vollständig von Nazis gereinigten Gemeindekanzlei, aufgebaut nach rein demokratischen Grundsätzen unter Berücksichtigung, daß nur einheimische Kräfte dort beschäftigt werden.

3. Bildung von Ausschüssen mit Spezialarbeitsgebieten, die sich über alle kommunalund gemeindepolitisch wichtigen Aufgabengebiete erstrecken müssen.

4. Eine den gegebenen Verhältnissen entsprechende scharfe Nachprüfung der Wohnungspolitik und gerechte Wohnraumverteilung.

5. Wahrung aller Interessen der Gemeindebevölkerung in sozialer und politischer Hinsicht. Errichtung einer Gemeindebibliothek.

6. Rücksichtslose Bekämpfung aller evtl. noch aus Nazikreisen kommenden Gegenströmungen.

7. Ergreifung wirtschaftlicher und ernährungspolitischer Maßnahmen zur Sicherung der Ernährung, im Zuge damit Hebung der Kleintierzucht und Erfassung brachliegender Flächen.

8. Der Bedarf an Wohnraum wird durch Wohnungsbau gedeckt.

9. Alle Fabriken und Handelsgeschäfte werden überprüft und alle für die Gemeinschaft wichtigen werden gefördert.

10. Erziehung der Jugend im streng demokratischen Sinn.“ 39

Die antifaschistischen Ausschüsse in Frankfurt, Stuttgart und den großen Städten des Ruhrgebietes erregten bald den Argwohn der Militärregierung. Erfüllt von revolutionär-sozialistischen Hoffnungen, beflügelt von der Erwartung, im zukünftigen Deutschland eine dominierende Rolle spielen zu können, und selbstbewußt im Auftreten, paßten sie nicht in das "Law and Order“-Konzept der Besatzungsmacht, die deshalb nicht selten zu rigorosen Mitteln griff und die Antifas einfach verbot. „Ich kenne diese Antifaschisten“, soll ein amerikanischer Offizier beim ersten Zusammentreffen mit dem Münchener Nationalkomitee Freies Deutschland gesagt haben, „das

38 Mündliche Mitteilung von Hans Wild vom 5. Januar 1984.

39 Ein unvollständiges Exemplar des Programms in deutscher Sprache befindet sich in: Privatbesitz Hans Wild, Oberasbach; ein vollständiges Exemplar in englischer Sprache liegt in: StA Nürnberg, LRA Fürth (1962), Nr. 149. 
sind alles Banditen." ${ }^{40} \mathrm{Ganz}$ anders die Situation in Oberasbach, wo das Komitee das volle Vertrauen der Militärregierung genoß. Kein Wunder, denn einige kommunistische Komiteemitglieder waren bei CIC beschäftigt, so daß die Militärregierung gleichsam mit am Tisch saß, wenn sich die Antifa-Mitglieder in der Küche von Wild versammelten und ihre nächsten Schritte besprachen. Im Unterschied zu den Antifas in urbanen Regionen mit starker Arbeiterbewegungstradition verstand sich die Oberasbacher Einheitsfront auch nicht als Vorbote oder Träger einer revolutionären Umwälzung, sondern ausschließlich als dörfliche Selbsthilfeorganisation und blieb wohl auch deshalb der Militärregierung unverdächtig. Zu den wichtigsten Aufgaben des Komitees zählten die Unterbringung der Flüchtlinge und die Beschlagnahme von Kleidung und Lebensmitteln, um die „Neubürger“ wenigstens mit dem Nötigsten versorgen zu können. Außerdem mußte es versuchen, die marodierenden DP's im Zaum zu halten, den Rücktransport der Evakuierten einzuleiten und die ersten Aufräumarbeiten im Dorf zu beginnen. „Es waren arbeitsreiche Tage, jeder von uns hat ja tagsüber gearbeitet“, erzählte Hans Wild später und fügte stolz hinzu: „Wir haben da Ordnung geschafft, das muß anerkannt werden." ${ }^{\text {11 }}$ Als im August 1945 mit Johann Gerharz ein neuer Bürgermeister gefunden war, zog sich das Komitee aus der Gemeindepolitik mehr und mehr zurück. Gerharz, ein parteiloser Ziegeleimeister, war von Sehlmacher vorgeschlagen worden. Er ließ sich noch einige Zeit von der Einheitsfront beraten, bis diese sich im Januar 1946 stillschweigend auflöste. Nicht wenigen Komiteemitgliedern, die 1945 die Initiative ergriffen hatten, wurde ihr Engagement für die Gemeinde in späteren Jahren schlecht gelohnt. Hans Wild, der sich inzwischen als Brunnenbauer und Wünschelrutengänger selbständig gemacht hatte, bekam in seiner Heimatgemeinde keine Aufträge. „Wir waren verfemt“, sagte Wild, der noch heute Vorwürfe wegen Vorkommnissen aus der damaligen Zeit zu hören bekommt ${ }^{42}$.

Col. William Whitaker, dem Chef der Militärregierung von Ansbach, blieben so negative Erfahrungen, wie sie 2nd Lt. Milton Solomon in Seukendorf machen mußte, erspart. Aber auch er hatte bald einsehen müssen, daß sein Detachment mit der Einsetzung von immerhin 82 neuen Bürgermeistern im Landkreis Ansbach überfordert war. Er überließ diese Aufgabe deshalb den Ansbachern selbst, d.h. dem Landrat, und gab somit schon frühzeitig ein Stück Besatzungs-Souveränität auf. Ansbachs Landrat Richard Neff, überrascht, mit so weitreichenden Kompetenzen ausgestattet zu werden, packte diese Aufgabe mit viel Geschick an. Der selbstbewußte Karrierebeamte, der seinen Landkreis fast ebensowenig kannte wie die amerikanischen Offiziere, wollte sich weder auf die Ratschläge der Kirchen, noch auf Empfehlungen der ortsbekannten NS-Gegner stützen, sondern suchte die Zusammenarbeit mit den im Aufbau befindlichen politischen Parteien. Er richtete im Landratsamt ein kleines Komitee ein, dem außer ihm selbst ein führender Mann der CSU, der ehemalige deutsche Botschafter in Tokio Ernst-Arthur Voretzsch, und der ehemalige Landtagsabgeordnete Forstamtmann Wilhelm Zimmerer von der SPD angehörten ${ }^{43}$. Von August bis Jahresende war das Komitee auf der Suche nach geeigneten Bürgermeisterkandidaten. Seine Vorge-

40 Zit. nach Lutz Niethammer, Die amerikanische Besatzungsmacht zwischen Verwaltungstradition und politischen Parteien in Bayern 1945, in: VfZ 15 (1967), S. 178.

41 Mündliche Mitteilung von Hans Wild vom 5. Januar 1984.

42 Ebenda.

43 Vgl. Amts- und Mitteilungsblatt des Landkreises Ansbach, 20. Februar 1952, S. 3. 
hensweise war einfach, aber erfolgreich: Neff, Voretzsch und Zimmerer bereisten die einzelnen Dörfer, beriefen Bürgerversammlungen ein und erkundeten das Meinungsspektrum in den Gemeinden.

Eine dieser Bürgerversammlungen fand am 31. Oktober 1945 in Leutershausen statt. Landrat Neff, der nur NS-Gegner eingeladen und mit etwa fünfzig Besuchern gerechnet hatte, war überrascht, rund 300 Besucher anzutreffen, die alle bei der Einsetzung des neuen Gemeindeoberhaupts mitmachen wollten. Zu Beginn der Versammlung unterstrich Neff, daß die Militärregierung die Wahl eines Bürgermeisters noch nicht gestattet habe, die Bürgerschaft könne also nur Vorschläge machen. Dann begann die öffentliche Diskussion, die schnell zeigte, daß die Versammelten den Landwirt Schultheiß als neuen Bürgermeister favorisierten. Neff hatte dagegen nichts einzuwenden, obwohl ihm kurz vorher zugetragen worden war, daß Schultheiß während der NS-Zeit Ortsbauernführer gewesen war. Andere Kandidaten, die von der Versammlung ins Spiel gebracht wurden, lehnte Neff ab, so etwa einen früheren Stadtrat, der an der Verleihung der Ehrenbürgerschaft für Hitler mitgewirkt hatte ${ }^{44}$. Noch bevor die Amerikaner Wahlen zuließen, waren also nicht nur die von ihnen eingesetzten Landräte, sondern die Bürgerschaft selbst - wenn auch nur mittelbar - an der Auswahl der Bürgermeister beteiligt worden. Innerhalb von fünf Monaten wurden im Landkreis Ansbach auf diese Weise in allen 82 Gemeinden die Bürgermeisterposten besetzt. „Nicht eine einzige vorgeschlagene Person war politisch nicht akzeptabel ... Nur wenige, sehr wenige Fälle, die der Landrat als fragwürdig ansah, wurden mit dem Büro der Militärregierung vor der Nominierung besprochen“, lobte die Militärregierung die Arbeit von Neff ${ }^{45}$.

Viele der „Neuen“ hatten bei Kriegsende daran mitgewirkt, sinnlose Zerstörungen zu verhindern und sich dabei so großes Ansehen erworben, daß sie gleichsam ein natürliches Anrecht auf den Bürgermeisterposten besaßen. Da außerdem fast alle aus dem örtlichen Milieu stammten, wurden die neuen Bürgermeister nur selten als Protektionskinder des Landrats oder der Besatzungsmacht hingestellt. Mit wenigen Ausnahmen hatten sie eine politisch weiße Weste und waren, wie sich später herausstellte, vom „Gesetz zur Befreiung von Nationalsozialismus und Militarismus“ vom 5. März 1946 nicht betroffen. Bei einem Durchschnittsalter von etwa 50 Jahren waren die meisten vom Kaiserreich und der Weimarer Republik geprägt worden ${ }^{46}$. Pflichtgefühl, Autorität und unpolitische Überparteilichkeit waren ihre Maxime. Die sozialdemokratischen Bürgermeister unterschieden sich darin von ihren bürgerlichen Kollegen kaum. Symptomatisch dafür ist die Antrittsrede des Oberbürgermeisters von Fürth, Hans Bornkessel, der betonte, er werde das Amt so führen, wie er „es als alter Beamter zu führen gewohnt“ war, „über den Parteien stehend, von den Grundsätzen der Billigkeit und Gerechtigkeit geleitet ${ }^{“ 47}$. Sich an die neuen Verhältnisse zu gewöhnen, fiel den meisten schwer, wie Schregle offen bekannte: „Die meisten von uns sind aus dem

44 Vgl. LR Ansbach an RegPräs, 20. November 1946, in: NA, RG 260, 9/124-3/17.

4 Annual Hist. Rep., Det. Ansbach, 1. September 1946, in: NA, RG 260, 10/80-3/6.

46 Die Angaben beziehen sich vor allem auf die 34 neuen Bürgermeister des Landkreises Fürth. Sozialstatistische Daten zu dieser Personengruppe finden sich in den Akten des Landratsamtes Fürth (vor allem in: LRA Fürth, EAP 027, 070/2, 9, 10, 14), in den Akten des Militärregierungsdetachments von Fürth sowie vereinzelt in der Presse. Zusätzliche Informationen verdanke ich den Einwohnermeldeämtern der Gemeinden.

47 Antrittsrede von OB Fürth vom 6. Juni 1946, in: Stadtverwaltung Fürth, EAP 025 a. 
wilhelminischen Staat herausgewachsen und alle waren wir an die Strenge des sogenannten autoritären Staates gewöhnt. Es ist daher für uns sehr schwer, erstens einmal den Sinn und das Wesen der Demokratie zu erkennen, uns mit allen Grundsätzen und Methoden vertraut zu machen und uns an ihre Gepflogenheiten zu gewöhnen. Es ist ja nicht so, daß man gewissermaßen das eine politische Evangelium weglegen und ein anderes dafür in Angriff nehmen und es sofort in einer mustergültigen Weise befolgen kann. “48

Nur eine kleine Minderheit der neuen Männer hatte vor 1933 gleiche oder ähnliche Posten innegehabt. Von den 34 Bürgermeistern im Landkreis Fürth waren 30 neu im Amt, nur in vier Gemeinden wurden die Verhältnisse von 1933 wieder hergestellt entweder auf Drängen der Einwohner, wie in Laubendorf, oder weil sich kein anderer Bürgermeister finden ließ, wie in Großhabersdorf, wo man sich nach langem Suchen schließlich daran erinnerte, daß der Bürgermeister der Jahre 1922 bis 1933 „,seinerzeit sein Amt mit größter Zufriedenheit verwaltet" hatte ${ }^{49}$. Am radikalsten war der personelle Wechsel in Ansbach. Mit Schregle, Körner und dem zufällig durchreisenden Neff kamen Außenseiter in leitende Positionen, die man es - anders als ihren aus dem Milieu stammenden Kollegen in den Dörfern - anfangs spüren ließ, daß sie von der Besatzungsmacht eingesetzt worden waren. Die Berufung der beiden Ansbacher Oberbürgermeister war auch insofern bemerkenswert, als damit das bis dahin geltende Juristenmonopol für Spitzenfunktionen in der kommunalen Verwaltung durchbrochen wurde. Gleiches läßt sich feststellen für den neuen Landrat von Fürth, den Unternehmer Hörndlein, und für seine Kollegen Johann Pösł in Vohenstrauß, der früher im Straßen- und Flußbauamt in Weiden beschäftigt gewesen war, und den gelernten Buchdrucker Konrad Kübler in Landau/Isar. Auch der spätere Abgeordnete im Landtag Andreas Mader, ein Studienrat, der zum Bürgermeister in Deggendorf ernannt worden war, der spätere Wirtschaftsminister und CSU-Vorsitzende, Hanns Seidel, den die Militärregierung zum Landrat von Aschaffenburg machte, und Franz Josef Strauß gehörten zur gar nicht kleinen Garde der neuen Leute, die nach Kriegsende mit Hilfe der Besatzungsmacht ihre Karriere begannen ${ }^{50}$.

Mit Blick auf die Verhältnisse in den Rathäusern und Landratsämtern der Provinz wird man folglich die in der wissenschaftlichen Literatur weitverbreitete, von Theodor Eschenburg in seinem Standardwerk ,Jahre der Besatzung 1945-1949“ erneut bekräftigte Feststellung, daß die „Erstausrüstung der deutschen Verwaltung“ nach dem Zweiten Weltkrieg „aus dem politischen und administrativen Personalreservoir der Weimarer Republik bestritten“" wurde, etwas korrigieren müssen ${ }^{51}$. Die Berufungspolitik der Amerikaner brachte hier neben alten politischen Eliten der Weimarer Zeit oder altgedienten, aber politisch unbelasteten Beamten auch viele Vertreter eines neuen Typus in Schlüsselpositionen der unteren und mittleren Verwaltung. „Viele Männer aus der Wirtschafts- und Finanzwelt“, so urteilte die Militärregierung von Ober- und Mittelfranken am 20. Juni 1946, „wurden durch die Militärregierung in den

48 Besprechung des RegPräs mit OB und LR, 20. März 1947, Prot. in: StA Nürnberg, Reg von Mittelfranken (1978, Zusatz), Nr. 25.

49 Gendarmerie-Kreis Fürth, 22. Mai 1945, in: LRA Fürth, EAP 150/8.

so Vgl. Amtliches Handbuch des Bayerischen Landtags, hrsg. vom Landtagsamt, München 1948, S. 107, 122, 145,173 .

51 Eschenburg, Jahre der Besatzung, S. 73. 
öffentlichen Dienst gebracht. Sie halfen, die alte autokratische Amtshaltung der früheren Verwaltung zu beseitigen. Dieser Zustrom von Personal, das nicht aus der Verwaltung stammte, wurde von den Deutschen sehr positiv beurteilt." $52 \mathrm{Daß}$ den neuen Männern einschlägige Berufserfahrung und spezielle Vorbildung fehlten, kümmerte die Offiziere der Militärregierung wenig, persönliche Integrität, Entschlußkraft und ein tadelloser politischer Leumund waren ihnen wichtiger.

Als Schregle, Wiesinger und Schwiening im April/Mai 1945 ihre neuen Amtsräume in den Rathäusern bezogen, konnten sie wohl kaum das Gefühl haben, die ersten Männer ihrer Gemeinde zu sein. Sie waren mit den neuen Aufgaben nicht vertraut, unsicher, weil der Kontakt zu den vorgesetzten Behörden fehlte, und überwältigt von der Fülle der Aufgaben, die früher bei Reich und Ländern gelegen hatten, jetzt aber in den Zuständigkeitsbereich der Gemeinden fielen. Außerdem konnten sie zunächst nur schwer einschätzen, ob sie das Vertrauen ihrer Landsleute besaßen und vor allem wie groß der eigene Spielraum unter der Herrschaft der amerikanischen Offiziere war, die vielen als unberechenbar erschienen. Hans Weiß, ein junger CSU-Politiker aus München, brachte die ständige Unsicherheit im Umgang mit der Besatzungsmacht im Herbst 1946 auf die drastische Formel: „An einem Tag kriegst du eine von links übers $\mathrm{Ohr}$, daß du bis in den Keller fällst, nach einigen Wochen oder Monaten packen sie dich am Kragen und stellen dich wieder auf die Beine. Aber du weißt nie, ob du in ein paar weiteren Tagen nicht wieder eine über die Ohren kriegst." ${ }^{53}$

Solche Wechselbäder blieben den neuen Amtsträgern in der Region um Ansbach und Fürth erspart, aber als „Kreiskönig“54 mit unbeschränkten Vollmachten fühlte sich wohl keiner; sie mußten sich erst langsam in ihre heikle Rolle zwischen den Fronten hineinfinden, die zuweilen viel Geduld und Nervenstärke erforderte. Schregle mußte anfangs fast täglich zu Lagebesprechungen im Hauptquartier der Militärregierung erscheinen. Bei diesen Besprechungen in der Promenade Nr. 4 herrschte ein militärisch knapper Ton, die deutschen Vertreter bekamen zu spüren, daß sie nicht Herr im eigenen Hause waren. Landrat Neff wurde das bereits beim Betreten des amerikanischen Hauptquartiers demonstriert, als er den Hintereingang nehmen mußte. Der Ansbacher Arbeitsamtsdirektor Karl Reichel, ein Sozialdemokrat, erhielt seine Befehle von einem US-Offizier, der ihn keines Blickes würdigte. Voller Geringschätzung saß dieser, eine dicke Havanna rauchend, hinter dem Schreibtisch und kehrte Reichel den Rücken zu. Jüdische Emigranten in den Reihen der Militärregierung, deren Muttersprache deutsch war, weigerten sich lange, mit ihren deutschen Gesprächspartnern auch nur ein Wort in deutscher Sprache zu wechseln ${ }^{55}$. Die Bevölkerung spürte natürlich, daß es mit der Autoritāt der „Neuen“ in den Rathäusern und Landratsämtern nicht weit her war, sie wandte sich deshalb bei Beschwerden und Ärgernissen lieber gleich an die Militärregierung. Das Rathaus verlor so vorübergehend seine traditionelle Funktion als zentraler Ort der „kleinen“ Politik. Wiesinger, der neue Bürgermeister von Roßtal, hatte mit den amerikanischen Offizieren seltener zu tun. Die Offiziere

32 Annual Hist. Rep., Det. für Ober- und Mittelfranken, 20. Juni 1946, in: NA, RG 260, 9/120-2/8.

53 Klaus-Dietmar Henke/Hans Woller (Hrsg.), Lehrjahre der CSU. Eine Nachkriegspartei im Spiegel vertraulicher Berichte an die amerikanische Militärregierung, Stuttgart 1984, S. 18.

s4 Eschenburg, Jahre der Besatzung, S. 73.

ss Mündliche Mitteilung von Karl Reichel vom 28. Oktober 1980 und schriftliche Mitteilung von Elisabet Neff vom 6. Juli 1981. 
fuhren zwar Tag für Tag viele Kilometer durch die Landkreise, an vielen Orten tauchten sie aber höchstens ein- oder zweimal pro Woche für einige Minuten auf, sahen kurz nach dem Rechten und verschwanden wieder. Vieles, was in den Dörfern und Ackerstädtchen passierte, entzog sich so ihrer Kenntnis.

Die Landräte und Bürgermeister der größeren Städte dagegen waren in den ersten Wochen nach der Besetzung kaum mehr als „überbezahlte MG-Laufburschen“56 der Militärregierungsoffiziere, die sich zunächst um alles selbst kümmerten. Professor Dorn, der im Auftrag von OSS im Sommer 1945 durch die amerikanische Zone reiste, beklagte damals, daß die Militärregierungsoffiziere zu stark in "die deutschen Dinge“ eingriffen. „Sie arbeiteten hart an Dingen, die ganz und gar nicht zu ihrer wirklichen Aufgabe gehörten ... Es galt überhaupt für eine große Anzahl von Fällen, wo unsere Leute, anstatt die Deutschen dazu zu bringen, die Aufgaben zu lösen und ihnen Verantwortung zu übertragen, in Wirklichkeit die Aufgaben selbst übernahmen." 57 Dabei stützte sich die Militärregierung meist auf eine größere Zahl von Hilfskräften aus dem Kreis der DP's, die als Dolmetscher, Schreibkräfte, Fahrer oder Kuriere fungierten und Schregle oder Schwiening mitunter noch deutlicher als die amerikanischen Offiziere demonstrierten, wer eigentlich das Sagen hatte.

Auch Einheimische mit guten Verbindungen zu den Amerikanern schwangen sich oft zu kleinen Potentaten auf. Vielen Fürthern ist z.B. der „Sonderdienst“ des KPFunktionärs Josef Gleixner im Gedächtnis geblieben. Gleixner, der sich im April 1945 zusammen mit Fritz Gastreich für die kampflose Übergabe der Stadt eingesetzt hatte, war nach Kriegsende schnell mit einigen CIC-Offizieren in Kontakt gekommen, die ihm bald ihr Vertrauen schenkten. Er residierte gleich neben der Militärregierung im Rathaus und fühlte sich wohl zeitweise als heimlicher Oberbürgermeister. Die Litewka tragend, tauchte er überall auf, wirkte bei Verhaftungen und Beschlagnahmen mit und setzte anfangs sogar Bürgermeister $e^{58}{ }^{58}$. In Ansbach trieb ein aus Nürnberg stammender Dolmetscher sein Unwesen, der bald nur noch „Herrscher von Ansbach“ genannt wurde. Ganz in Leder gekleidet patrouillierte er mit Schäferhund und Reitpeitsche durch die Stadt und verbreitete Furcht und Schrecken. Seine Machtfülle schien unbegrenzt; er beschlagnahmte Wohnungen, Lebensmittel und Einrichtungsgegenstände. „Die hätten einen umbringen können“, so kann man noch heute in Ansbach hören, wenn die Rede auf die entnervenden ersten Wochen der Besatzungszeit kommt $^{59}$.

Daß sie es in ihren neuen Ämtern schwer haben würden, damit hatten Wiesinger, Schregle und Schwiening gerechnet. Ein Besatzungsoffizier hatte Schregle schon bei der Amtseinsetzung gesagt: „Sie werden es nicht leicht haben, denn wir sind nicht als Ihre Befreier gekommen, sondern als Sieger in Ihr Land gezogen."60 Trotzdem waren die neuen deutschen Amtsinhaber nicht darauf gefaßt gewesen, daß nach $2 \frac{1}{2}$ Monaten Besatzungsherrschaft plötzlich in der politischen Säuberung eine radikal verschärfte Gangart angeschlagen würde, die vielen Beamten und Angestellten den Arbeitsplatz kostete.

36 Denkschrift von Pollock, in: Dorn, Inspektionsreisen, S. 56.

37 Ebenda, S. 44 f.

58 Schriftliche Mitteilungen von Alfred Schmidt vom 3. Dezember 1984 und 5. Februar 1985.

59 Mündliche Mitteilungen von Ludwig Schönecker vom 17. August 1983, Wilhelm Eichhorn vom 17. August 1983 und Karl-Heinz Sening vom 13. Juni 1983.

60 Besprechung des RegPräs mit OB und LR, 6. Mai 1946, Prot. in: StA Nürnberg, LRA Scheinfeld, Nr. 367. 


\section{Die politische Säuberung des öffentlichen Dienstes: Maßnahmen, Widersprüche, Reaktionen}

Mit Hans Schregle, Friedrich Böhner und Friedrich Wilhelm Beuschel trafen in den letzten Apriltagen des Jahres 1945 im Ansbacher Stadthaus drei alte Bekannte zusammen. Der neue sozialdemokratische Bürgermeister schätzte den ehemaligen Parteigenossen Böhner, den er in den zurückliegenden Jahren als besonnenen und mutigen Mann kennengelernt hatte. Vor allem hatte ihm Böhners Haltung im evangelischen Kirchenkampf imponiert, als dieser trotz aller Anfeindungen seiner Partei im Kirchenvorstand geblieben war $^{61}$. Schregle gab ihm deshalb mit Billigung der Militärregierung das Amt des 2. Bürgermeisters zurück, das Böhner 1934 auf Druck von Oberbürgermeister Hänel hatte aufgeben müssen. Seit seiner Strafversetzung nach Ansbach stand Schregle auch mit dem Finanzexperten Beuschel, der schon fast vier Jahrzehnte in der Stadtverwaltung arbeitete, in gesellschaftlichem Kontakt. Beuschel hatte vor 1933 der Demokratischen Partei und der Freimaurerloge „Alexander zu den 3 Sternen" angehört und sich danach der NSV, dem NSDAP-Opferring und einigen NSStandesorganisationen angeschlossen ${ }^{62}$. Auch die übrigen Spitzenbeamten der Stadtverwaltung waren für das neue Stadtoberhaupt keine Unbekannten. Vor allem mit den Freimaurern, dem städtischen Bezirkstierarzt Georg Betscher, dem Personalreferenten Christian Stecher und dem Direktor der Stadtwerke Willy Götz, die Oberbürgermeister Hänel stets „gegen Anfeindungen und Angriffe aus den Kreisen der Partei“63 gedeckt hatte, war er in den zurückliegenden Jahren häufig zusammengetroffen. Und von den leitenden Beamten, die 1933 der NSDAP beigetreten waren, wußte er, daß sie auch dann noch anständige Männer geblieben waren, als sie längst das Parteibuch der NSDAP in der Tasche hatten.

Wo, wie in der Stadtverwaltung Ansbach, kaum alte Rechnungen aus der NS-Zeit zu begleichen waren, mußte nach 1945 die große Abrechnung ausbleiben. Wie auch in vielen anderen Städten und Regionen des besetzten Deutschlands begnügten sich die neuen Chefs weitgehend damit, daß die führenden Repräsentanten des NS-Systems geflohen oder von den Besatzungsmächten verhaftet worden waren. Ihre Säuberungsbemühungen zielten fast ausschließlich auf windige Denunzianten oder „Alte Kämpfer“, die aufgrund ihrer langjährigen Parteizugehörigkeit und „wegen der Verdienste um die nationale Erhebung des deutschen Reiches“ in die Verwaltung übernommen worden waren und sich später als scharfe Hunde entpuppt hatten. So ging man beispielsweise in München, Augsburg und Nürnberg vor, wo die neuen Oberbürgermeister sogleich nach ihrem Amtsantritt kleine Säuberungskomitees einrichteten. Auch im Regierungsbezirk Arnsberg ordnete Regierungspräsident Fritz Fries am 16. Mai 1945 an, alle „Alten Kämpfer“ aus dem öffentlichen Dienst zu entlassen. „Die Bevölkerung hat ein Recht zu verlangen“, so seine Argumente, „daß ein sogenannter ,Alter Kämpfer keine Stunde mehr im Dienst bleibt, weil er doch zu den Hochverrätern und Umstürzlern des demokratischen republikanischen Staates gehört hat." ${ }^{\text {"64 }}$ Mit den

$61 \mathrm{Vgl}$. Amtsgericht Ansbach, Registratur S: Nr. 4.

62 Ebenda: Nr. 5.

63 So Böhner am 20. November 1947 in einer eidesstattlichen Erklärung, in: Ebenda: Nr. 1.

64 Wolfgang Krüger, Entnazifiziert! Zur Praxis der politischen Säuberung in Nordrhein-Westfalen, Wuppertal 1982, S. 26. Vgl. auch ebenda, S. 24 f. 
gleichen Vorstellungen begann man die politische Säuberung auch im Innenressort der Landesverwaltung von Württemberg-Hohenzollern; hier betrieb man - lange bevor Weisungen der Militärregierung vorlagen - die „Dienstentlassung der prominenten Verbrecher der Nazipartei, der sogenannten alten Kämpfer, sowie anderer Ideenträger des verbrecherischen Wahnsinns“65.

Der Bürgermeister der sozialdemokratischen Hochburg Zirndorf hielt sich an ähnliche Grundsätze. Zwei Schulhausmeister, beide Träger des goldenen Parteiabzeichens der NSDAP, und ein Amtsbote, Pg seit 1928, mußten im Mai 1945 ihre Posten räumen. Weiter wollte der neue sozialdemokratische Bürgermeister in Zirndorf nicht gehen, alle „Märzgefallenen“ oder später der NSDAP beigetretenen Beamten, die als „anständig“ bekannt waren, konnten im Amt bleiben ${ }^{66}$. Auch in Fürth behielten Dutzende von Pgs, die sich politisch nicht exponiert hatten, ihre Posten - sehr zum Ärger der politisch Verfolgten, die sich im Herbst 1945 im Sonderministerium in München über Oberbürgermeister Schwiening, selbst Pg, beschwerten: „Man sagt, daß er in bestem Einvernehmen mit dem Herrn Kommandanten gelebt u. ganz bestimmt seinen Einfluß für die Nazisten in hervorragender Weise geltend gemacht hat. ${ }^{67}$ Er wisse wohl, so versuchte Ansbachs Oberbürgermeister Hans Schregle in der ersten Sitzung des Beratenden Ausschusses am 18. September 1945 diese weiche Linie der neuen Männer an der Spitze der Verwaltung zu erklären, „daß damals da und dort der Vorwurf vernehmlich war, wir wären in der Entfernung der Nazis nicht allzu rasch vorgegangen ... Von außen gesehen, und das gilt allgemein, sehen die Dinge viel einfacher aus als von innen betrachtet. Wir haben in den Jahren vorher das Umstürzlerische hinreichend kennengelernt und wir mußten uns zu dem bekennen, daß mit Umstürzen die Dinge nicht besser, sondern schlechter gemacht werden." 68

Wie sich die Amerikaner die politische Säuberung der Beamten und Angestellten vorstellten, war den Deutschen zunächst nicht klar. Für eine systematische Entnazifizierung waren die überlasteten Militärregierungseinheiten im Frühjahr 1945 weder personell noch organisatorisch gerüstet. Nicht einmal die berühmten Fragebogen standen den Detachments in genügender Zahl zur Verfügung. Und schließlich fehlte es ihnen auch noch nach der Kapitulation an einheitlichen Säuberungsrichtlinien ${ }^{69}$. Die

65 Klaus-Dietmar Henke, Politische Säuberung unter französischer Besatzung. Die Entnazifizierung in Württemberg-Hohenzollern, Stuttgart 1981, S. 26.

66 Vgl. Bg Zirndorf an LR Fürth, 22. Mai 1945 und 7. Juni 1945, in: LRA Fürth, EAP 027. Vgl. Det. Fürth an LR Fürth, 31. Juli 1945, in: Ebenda.

${ }^{67}$ Betreuungsstelle der Opfer des Nazismus, Fürth an Staatsrat Schmitt, München, 3. November 1945, in: Stadtverwaltung Fürth, EAP 06.

68 Prot. in Stadtverwaltung Ansbach, Registratur des OB.

69 Joseph R. Starr, U.S. Military Government in Germany: Operations from Late March to Mid-July 1945, Karlsruhe 1950, S. 129-133. Die Ausschaltung von belasteten Parteigenossen war nur eines der beiden Ziele, die sich die Amerikaner im Hinblick auf den öffentlichen Dienst in Deutschland gesteckt hatten. Zugleich beabsichtigten sie, eine Reform des öffentlichen Dienstes im Zeichen einer durchgreifenden Dezentralisierung und im Geiste liberaldemokratischer Prinzipien einzuleiten. Die Bemühungen der Militärregierung, den deutschen Verwaltungen gleichsam einen demokratischen Geist einzuhauchen, fanden bei allen maßgebenden politischen Kräften Bayerns Anklang. Insbesondere Ministerpräsident Hoegner trat energisch dafür ein, daß auch die Gemeinden und Kreise „ein wenig auf eigenen Füßen stehen innerhalb des großen deutschen Ganzen“. Vgl. Unser Weg, S.14. Zit. nach Wolfgang Behr, Sozialdemokratie und Konservatismus. Ein empirischer und theoretischer Beitrag zur regionalen Parteianalyse am Beispiel der Geschichte der Nachkriegsentwicklung Bayerns, Hannover 1969, S. 166. Eine Reihe dieser Neuerungen fand so Eingang in die Bayerische Gemeindeordnung von 1945/46, in der im wesentlichen die Stadtratsverfassung aus der Zeit vor 1933 wiederhergestellt wurde. Künftig sollte der Gemeinderat wieder das dominierende gemeindliche 
„Wolke der Unsicherheit" ${ }^{\text {"70 }}$ um das Entnazifizierungsproblem, die schon den Planungsstäben in den USA viel Kopfzerbrechen bereitet hatte, verdichtete sich eher noch. Zeitweise waren mehrere, einander widersprechende Entnazifizierungsdirektiven in Kraft: eine scharfe Direktive des Supreme Headquarter, Allied Expeditionary Forces (SHAEF), zwei noch drastischere Verordnungen der 6. und 12. Armeegruppe, denen zufolge Parteimitglieder gewichtige Stellungen im öffentlichen Dienst grundsätzlich verschlossen waren, und außerdem die etwas moderateren Richtlinien des „Handbook“, mit dessen Bestimmungen die Offiziere in den Ausbildungszentren in Großbritannien und den USA vertraut gemacht worden waren. Seine revidierte Fassung, die erst in letzter Minute in die Hände der Public Safety-Offiziere gelangt war, verlangte, wie die Direktiven von SHAEF und der Armeegruppen, die Auflösung der NSDAP und die Einziehung des Vermögens von NS-Organisationen, wich aber von den anderen Anweisungen insofern ab, als sie abgesehen von den Spitzen von Partei und Staat, pauschale Maßnahmen gegen Parteigenossen vorsah, die sich vor 1933 der NSDAP angeschlossen hatten ${ }^{71}$.

Da die amerikanischen Detachments vor Ort zunächst nur selten auf Entlassungen gedrängt, zudem viele Beamte vom Typ eines Böhner im Amt beschäftigt, ja sogar - in Einzelfällen - Pgs wie Schwiening und Borkholder zu Bürgermeistern und Landräten gemacht hatten, konnten die neuen und alten deutschen Amtsträger hoffen, daß die politische Säuberung keine weiten Kreise ziehen werde. „Die Amerikaner hätten sich nunmehr“, so glaubte Regierungspräsident Reichard am 21. Juni 1945 den Landräten

Selbstverwaltungsgremium sein, die Wahl seiner Mitglieder sollte nach dem Verhältniswahlrecht erfolgen. „Wie schon nach dem Gemeindewahlgesetz von 1924, war der erste Bürgermeister in Gemeinden bis zu 3000 Einwohnern unmittelbar von der Gesamtheit der Wahlberechtigten zu wählen, in den anderen Gemeinden vom Gemeinderat.“ Vgl. Ulrich Probst, Die Entwicklung der gemeindlichen Selbstverwaltung in Bayern, Würzburg 1957, S.162. Der Grundsatz der unmittelbaren Wahl wurde 1948 schließlich auf Gemeinden bis zu 10000 Einwohnern ausgedehnt. Auch im Bereich der Landkreisordnungen drängte die Militärregierung auf eine Stärkung der nach der nationalsozialistischen Gleichschaltungsphase aufgelösten Vertretungskörperschaften der Landkreise. Das hervorstechendste Merkmal der neuen bayerischen Landkreisordnung vom 18. Februar 1946 war, daß der Landrat, der sowohl in der Weimarer als auch der NS-Zeit von der Zentralregierung in München ernannt worden war, von nun an vom Kreistag gewählt werden sollte. Die auf Anstoß der Besatzungsmacht geschaffenen rechtlichen Grundlagen der Verwaltung blieben bis zur Gebietsreform in Bayern 1972 erhalten. Die einzigen größeren Reformen datieren aus dem Jahre 1952, als die Direktwahl von Bürgermeistern in Gemeinden über 10000 Einwohnern und Landräten eingeführt wurde. Vgl. dazu Gesetz Nr. 32 vom 18. Februar 1946: Landkreisordnung, in: BGVBI. 17/1946 und BGVBI. 5/1952. Zu den amerikanischen Versuchen, den deutschen öffentlichen Dienst zu reformieren vgl. Wolfgang Benz, Versuche zur Reform des öffentlichen Dienstes in Deutschland 1945-1952, in: VfZ 29 (1981), S. 216-245. Vgl. auch Rudolf Morsey, Personal- und Beamtenpolitik im Ubergang von der Bizonen- zur Bundesverwaltung (1947-1950), in: ders. (Hrsg.), Verwaltungsgeschichte. Aufgaben, Zielsetzungen, Beispiele, Berlin 1977, S. 191-238 und Theodor Eschenburg, Der bürokratische Rückhalt, in: Richard Löwenthal/Hans-Peter Schwarz (Hrsg.), Die Zweite Republik. 25 Jahre Bundesrepublik Deutschland - eine Bilanz, Stuttgart 1974, S. 64-94.

70 John G. Korman, U.S. Denazification Policy in Germany, 1944-1950, Bad Godesberg 1952, S. 21.

71 Vgl. dazu Starr, Military Government, S. 36 ff.; Henke, Politische Säuberung unter französischer Besatzung, S. 20 ff. In der Anfangsphase der Besatzung hatten die Militärregierungsoffiziere "keine klare Vorstellung von der offiziellen Entnazifizierungspolitik“. Ulrich Borsdorf/Lutz Niethammer (Hrsg.), Zwischen Befreiung und Besatzung, Wuppertal 1976, S.173. „The detachments were forced to wrestle with the exigencies of the situation and it was not surprising that as a result of inadequate training, haphazardly selected personnel and policy uncertainty, they were ill-prepared to take over the difficult job of controlling German government. Nowhere did this situation become more apparent than in the sphere of denazification. The average Military Government officer was lost in a maze of National Socialist organizations and uniforms. In some instances, the very flamboyance of a uniform alone was enough to convince the inexperienced officer that the wearer must have been a dangerous Nazi.“ Korman, Denazification Policy, S. 22 f. 
und Oberbürgermeistern seines Regierungsbezirkes in Ansbach mitteilen zu können, „aufgrund eigener Anschauung von der anständigen Gesinnung der großen Mehrzahl der Deutschen überzeugt. Man dürfe daher wohl auch in absehbarer Zeit auf eine Milderung der Bestimmungen über den Personalbau rechnen. Charakterlich und fachlich einwandfreie Dienstkräfte würden voraussichtlich wieder zugelassen werden, selbst dann, wenn sie schon vor dem Jahr 1933 Mitglieder der Partei waren." ${ }^{\text {"72 }}$ Auch die Grundsätze der Personalpolitik, die der bayerische Ministerpräsident Fritz Schäffer im Juni 1945 bekanntgegeben hatte, wirkten beruhigend. Danach sollten nur leitende Stellen nicht mit Parteigenossen besetzt werden. Pgs, „die sich als solche nicht betätigt haben und charakterlich und fachlich einwandfrei sind“, dürften widerruflich angestellt werden ${ }^{73}$.

Währenddessen lief die amerikanische Entnazifizierungsmaschinerie langsam an. Im Mai/Juni wurden die Fragebogen mit ihren mehr als hundert Fragen nach Lebenslauf, Beruf und Mitgliedschaft in NS-Organisationen an Beamte und Angestellte ausgegeben und von den Detachments überprüft. Ende Juni erfolgten dann die ersten Entlassungen. „In den letzten Tagen ... mußten etwa 75-80 Beamte, Angestellte und Arbeiter, die vor dem 1. April 1933 Parteigenossen waren, entlassen werden“, teilte der Oberbürgermeister von Fürth dem Regierungspräsidenten mit ${ }^{74}$. Die Militärregierung hielt sich dabei an die Bestimmungen des Handbuchs, während die scharfe SHAEF-Direktive nicht befolgt wurde. Das war aber nur das Vorspiel. Wenig später, am 7. Juli 1945, erließ USFET eine neue Direktive, die den bisherigen Säuberungskurs drastisch verschärfte. Die Verschärfung kam für die überwiegend pragmatischen Militärregierungsoffiziere vor Ort ebenso überraschend wie für die Deutschen. Sie erfolgte nicht aufgrund ,inhaltlicher Neubesinnung oder Einsicht in praktische Mängel der Säuberungsrichtlinien, sondern sie diente in erster Linie der Besänftigung der öffentlichen Meinung in den USA ${ }^{\text {"75 }}$, die insbesondere durch spektakulär aufgemachte Presseberichte von Anfang 1945 über angebliche Entnazifizierungspannen in Aachen der ersten, von den Amerikanern besetzten deutschen Stadt - aufgeschreckt worden war. Meldungen der New Yorker Zeitung „PM“ hatten damals den Eindruck erweckt, als arbeite die Militärregierung eng mit Nationalsozialisten zusammen und betrüge so die Gl's um ihre Kriegsziele ${ }^{76}$.

Die Entnazifizierungsbestimmungen der neuen Direktive bezogen sich auf die prominenten Vertreter der Industrie und der wirtschaftlichen Verbände und vor allem auf die Inhaber politischer Ämter sowie die Angehörigen des öffentlichen Dienstes, der gründlich von NS-Einflüssen gereinigt werden sollte. Sofort zu entlassen waren u.a. alle Pgs, die vor Erlaß des Reichsbeamtengesetzes vom 1. Mai 1937 der NSDAP beigetreten waren, alle Amtsträger von NS-Organisationen sowie alle höheren Beamten, Regierungspräsidenten, Landräte und Bürgermeister in den Gemeinden, und „zwar ohne Rücksicht auf etwaige Mitgliedschaften in NS-Organisationen "77. Daneben gab

72 Besprechung des RegPräs mit OB und LR, 21. Juni 1945, Prot. in: Stadtarchiv Ansbach, ABc T/5/3.

73 RegPräs Reichard gab in einer Besprechung mit OB und LR vom 21. Juni 1945 die Grundsātze Schäffers bekannt, Prot. in: Ebenda.

74 OB Fürth an RegPräs, 3. Juli 1945, in: Stadtverwaltung Fürth, EAP 4.

75 Henke, Politische Säuberung unter französischer Besatzung, S. 16f. Zur Entstehungsgeschichte der USFETDirektive, die z.T. auch auf die neue Direktive JCS 1067 zurückging, vgl. Niethammer, Entnazifizierung, S. 147-150.

76 Vgl. Niethammer, Zwischen Verwaltungstradition und politischen Parteien, S. $175 \mathrm{f}$.

77 Niethammer, Entnazifizierung, S. 153. 
es eine Reihe von Zweifelsfällen, in denen die Special Branch-Offiziere Entlassungen in das Ermessen der Militärregierungsoffiziere stellten. Die Juli-Direktive war der entscheidende Schritt zu einer unsystematischen Eskalation der Säuberungsvorschriften, „die jeder vernünftigen inneren Begründung entbehrte(n) ${ }^{478}$. Gegenüber den Bestimmungen des „Handbooks“ bedeutete sie eine gewaltige Ausweitung des Betroffenenkreises.

Nach dem Erlaß der Juli-Direktive ging es Schlag auf Schlag, in Landkreis- und Stadtverwaltungen lichteten sich die Reihen der Angestellten und Beamten. Münchens Oberbürgermeister Karl Scharnagl mußte bereits bis zum Frühsommer 1945 ein Viertel des gesamten Personals entlassen, in Nürnberg erhielt jeder dritte, in Bamberg jeder zweite Beschäftigte die Entlassungspapiere, und in Würzburg konnten nur etwa 30 Prozent der Beamten auf ihren Posten bleiben ${ }^{79}$. Auch die Ministerien in München blieben nicht verschont; besonders hart betroffen waren das Landwirtschafts- und das Finanzministerium. Das Finanzministerium mußte ein Drittel aller höheren Beamten entbehren; im Zuständigkeitsbereich des Oberfinanzpräsidiums München waren nur noch 39 von 68 Finanzämtern funktionsfähig, im Bereich des Nürnberger Oberfinanzpräsidiums sogar nur noch 18 von $59^{80}$.

Der Oberbürgermeister von Fürth schickte am 4. August 1945 einen alarmierenden Bericht an den Regierungspräsidenten: Nachdem schon im Vormonat 75-80 Beamte entlassen werden mußten, „ist der Stadtverwaltung nun eine weitere Liste übergeben worden, mit der Weisung, die darin genannten 89 Beamten ebenfalls sofort zu entlassen. Bei diesen Beamten handelt es sich um Mitglieder der NSDAP, mit dem Eintrittsdatum bis 1.5.1937. Diese Entlassungen bedeuten für die Stadtverwaltung, daß die Abwicklung der Geschäfte in geordneten Bahnen den allergrößten Schwierigkeiten begegnen wird, ja, daß bedenkliche Stockungen eintreten werden ... Mehrere Amts- und Abteilungsvorstände sind aufgeführt, die allein in der Lage sind, nach den grundlegenden Weisungen des Oberbürgermeisters oder der Referenten das ihnen übertragene Teilgebiet der Verwaltung selbständig und tadellos zum Wohle der Bevölkerung $\mathrm{zu}$ bearbeiten ... Sie sind im allgemeinen durch andere Beamte oder gar durch berufsfremde Personen nicht zu ersetzen ... Weitere 10 Beamte und Angestellte sind seit dem letzten Bericht noch in Haft genommen worden. “81 Im September verlautete aus dem Fürther Rathaus: „Die Militärregierung hat neuerdings Listen zu weiteren Entlassungen übergeben. Im ganzen sind nunmehr aus dem Bereich der Stadtverwaltung 160 Beamte, 26 Angestellte und Arbeiter ihres Dienstes enthoben worden. Durch diese Maßnahme sind bei der Mehrzahl der städtischen Ämter die denkbar größten Schwierigkeiten entstanden. Einzelne Abteilungen sind gänzlich verwaist. Bei der Lebensmittelpolizei, dem Grundstückeamt, dem Gesundheitsamt fehlen sämtliche Beamte. Beim Ernährungsamt wurden neben dem Geschäftsführer alle Abteilungsvorstände entlassen, ebenso die Vorstände der städtischen Kämmerei, des Versicherungsamtes, in der Hauptsache auch bei den Bauämtern, beim Wohlfahrtsamt und Kriegsschädenamt sind die Entlassungen tief einschneidend.“82

${ }^{8}$ Henke, Politische Säuberung unter französischer Besatzung, S. 23. Vgl. USFET-Direktive vom 7. Juli 1945, in: IfZ-Archiv, MA 1479/14.

79 Vgl. Niethammer, Entnazifizierung, S. $181 \mathrm{f}$

80 Ebenda, S. 182.

81 OB Fürth an RegPräs, 4. August 1945, in: Stadtverwaltung Fürth, EAP 4.

82 OB Fürth an RegPräs, 4. September 1945, in: Ebenda. 
Einem Teil der amerikanischen Offiziere kam die scharfe Juli-Direktive nicht ungelegen. Unpolitische Militärs zumeist, die sich bei Kriegsende für den Dienst in der zivilen Militärregierung hatten anwerben lassen, waren sie mit der Auslegung der komplizierten Bestimmungen des Handbuchs nicht zurechtgekommen. Die Behandlung vieler zweifelhafter Fälle hatte ihr Urteilsvermögen überstiegen, sie hofften auf eine eindeutige Anweisung: „The only directive I need, is to be ordered to destroy naziism in my area, with that I can clean out the nazi element, those people who could be considered as ,The Party" regardless of their date of entry, position etc. ${ }^{\text {"83 }}$ Im Gegensatz dazu empfand der Chef der Fürther Militärregierung, Captain Cofer, die Juli-Direktive als viel zu weitgehend. Der nüchterne Demokrat aus Texas wußte nur zu gut, daß dem säuberungspolitischen Hauruck-Verfahren Gerechte und Ungerechte gleichermaßen zum Opfer fielen: der Oberinspektor, der sich erst 1937 nach langem Zögern und heftigem Drängen seines Vorgesetzten zum Parteieintritt entschlossen hatte, ebenso wie der hitlergläubige Steuersekretär, der noch vor einem halben Jahr mit ganzer Kraft zum vermeintlichen Endsieg beigetragen hatte. Bekümmert über die zahlreichen Ungerechtigkeiten faßte Cofer den Entschluß, die politische Säuberung nicht über die Köpfe der deutschen NS-Gegner hinweg durchzuführen, die mit den Verhältnissen während der NS-Zeit bestens vertraut waren und beurteilen konnten, wer als aktiver Nationalsozialist anzusehen war. In den ersten Augusttagen unternahm er deshalb eine spektakuläre Aktion, die zur offiziellen amerikanischen Politik im krassen Gegensatz stand. Er rief die Spitzen der Stadtverwaltung und einige Mitglieder der antinazistischen Gruppen zusammen und besprach mit ihnen die Bildung eines Ausschusses, der die Militärregierung bei der Entnazifizierung beraten sollte. Der Ausschuß, dem zwei Sozialdemokraten, ein Kommunist, ein Liberaler und zwei Parteilose angehörten, konstituierte sich am 15. August. Cofer wurde von seinen Vorgesetzten aber schnell zurückgepfiffen, und der Ausschuß mußte seine Arbeit, ehe sie richtig begonnen hatte, wieder abbrechen ${ }^{84}$.

Da sich aufgrund dessen in den oberen Stäben der Militärregierung Zweifel am Säuberungswillen Cofers ergèben hatten, mußte der Chef der Fürther Militärregierung in den folgenden Monaten doppelt vorsichtig sein, um nicht erneut aufzufallen. Nur so ist es wohl zu erklären, daß sich in Fürth die Dinge vom Schlechten zum Schlimmen wendeten. Cofer traf nun sogar Entnazifizierungsregelungen, die noch über die geltende Direktive vom 7. Juli 1945 hinausgingen. „Ganz ausgeschlossen! Unter keinen Umständen dürfen Parteigenossen (egal zu welchem Zeitpunkt sie der Partei beigetreten sind), Sympathisanten des Nationalsozialismus, Profiteure des NS-Regime etc. im Landratsamt oder im Landkreis beschäftigt werden“, wies er am 10. September 1945 den Fürther Landrat an $^{85}$. In dessen Amt mußten daraufhin tatsächlich „alle Beamten und Angestellten, die Mitglieder der NSDAP waren, ohne Rücksicht auf das Eintrittsdatum oder ihre Stellung in der Partei, entlassen werden“"86.

83 Viele Offiziere āußerten sich in diesem Sinne. Vgl. Annual Hist. Rep., Det. für Ober- und Mittelfranken, 20. Juni 1946, in: NA, RG 260, 9/120-2/8.

84 Vgl. Weekly Summary, Det. Fürth, 4. August und 25. August 1945, in: NA, RG 260, 9/96-2/12.

${ }^{85}$ In: LRA Fürth, EAP 070/1.

86 BayHStA, Reg von Mittelfranken, Berichterstattung 1945, AZ 1-64, Bd. 7. Ebenso mußten viele Beamte und Angestellte in den Kleinstädten und Dörfern ihre Büros räumen; in Zirndorf etwa auch ein Schulhausoffiziant und ein Fleischbeschauer, beide Pgs seit 1937. Vgl. Det. Fürth an LR Fürth, 31. Juli 1945, in: LRA Fürth, EAP 027 und Ortschronik der Stadt Zirndorf, in: Rathaus Zirndorf. 
Auch die Stadtverwaltung von Fürth bekam die erzwungene Wendung Cofers zu spüren. Ende September erhielt der Oberbürgermeister erneut eine lange Liste mit den Namen von 90 Personen, „die mit sofortiger Wirksamkeit zu entlassen“ waren. „Unter diesen Neuzuentlassenden befinden sich allein 53 Angestellte und Arbeiter der Stadtwerke“, schrieb der Oberbürgermeister und faßte zusammen: „Die ausgesprochenen Personalentlassungen bei der Stadtverwaltung belaufen sich nunmehr auf 164 Beamte, 100 Angestellte und 68 Arbeiter. ${ }^{\text {" } 77}$ Ende Oktober 1945 hatte bereits die Hälfte aller pensionsberechtigten Bediensteten der Stadt Fürth die Entlassungspapiere erhalten $^{88}$. Ganz ähnlich sah es im Landratsamt in Ansbach aus, in dem bei Kriegsende 66 Beamte, Angestellte und Arbeiter beschäftigt gewesen waren. „Hiervon wurden durch die Militärregierung bis Ende 1945 insgesamt 30 Personen entlassen“, klagte der Landrat ${ }^{89}$. Nicht besser erging es den Beamten der Regierung von Mittelund Oberfranken in Ansbach: „Der Dienstbetrieb bei der Regierung kann nur mit Mühe aufrechterhalten werden“, berichtete der Regierungspräsident am 19. November 1945 an die bayerische Staatsregierung in München. Vor der Besetzung waren 38 Beamte des höheren Dienstes beschäftigt gewesen, jetzt waren es nur noch 10 . Von den ehemals 74 Beamten des gehobenen und mittleren Dienstes waren 13 übriggeblieben, von den 4 Beamten des einfachen Dienstes einer. Bei den Angestellten kam es zwar ebenfalls zu zahlreichen Entlassungen, hier konnten die Lücken aber durch Neueinstellungen schnell wieder geschlossen werden ${ }^{90}$.

Unter den Entlassenen befanden sich gewiß viele ehemalige begeisterte Nationalsozialisten, die mit dem Parteiabzeichen am Revers zum Dienst erschienen waren, Andersdenkende schikaniert hatten und bei den Veranstaltungen der Partei in der ersten

87 OB Fürth an RegPräs, 4. Oktober 1945, in: Stadtverwaltung Fürth, EAP 4.

88 Vgl. Weekly Summary, Det. Fürth, 3. November 1945, in: NA, RG 260, 9/96-2/13.

89 Amts- und Mitteilungsblatt des Landkreises Ansbach, 20. Februar 1952, S. 18. Vgl. auch LR Ansbach an RegPräs, Monatsbericht für Oktober 1945, in: LRA Ansbach, EAP 01-016. Vgl. Anlage 1 des Annual Hist. Rep., Det. Ansbach, 1. September 1946, in: NA, RG 260, 10/80-3/6. Insgesamt sprach das Ansbacher Detachment bis zum 1. September 1946 etwa 900 Entlassungen aus: u.a. 137 bei den Spar- und Darlehenskassen, 41 beim Finanzamt, 95 bei den Postämtern, 62 bei der Stadtverwaltung, 29 bei den Stadtwerken. Dies waren rund 50 Prozent aller vor der Besetzung beschäftigten Beamten, Angestellten und Arbeiter. Neben den höheren und mittleren Beamten der Verwaltung hatten die Lehrer am meisten unter den pauschalen Entlassungen zu leiden. Im Bereich der Schulverwaltung von Fürth wurden zunächst fast alle Lehrkräfte fristlos entlassen. Vgl. Mehrjahresbericht (1945-1955) der Schulverwaltung Fürth, in: Stadtverwaltung Fürth, EAP 211. Nicht anders war es in den Bereichen des Bezirks- und des Stadtschulamtes Ansbach, wo insgesamt 144 Lehrer gehen mußten. Vgl. Anlage 1 des Annual Hist. Rep., Det. Ansbach, 1. September 1946, in: NA, RG 260, 10/80-3/6. Kaum besser erging es den Beamten und Angestellten des Finanzamtes, der Staatsanwaltschaft, der Landwirtschaftsstelle, des Landbauamtes und des Wasserwirtschaftsamtes. Dagegen wurden die Beamten und Angestellten von Reichsbahn und -post zunächst sehr milde behandelt. Im Interesse der Aufrechterhaltung der Lebensmittelversorgung sah sich die Militärregierung in diesen Bereichen gezwungen, besondere Regelungen zu treffen, so daß - wie der Fürther Landrat im Dezember 1945 anmerkte - bei Reichsbahn und -post „Leute, die seit 1933 der Partei angehörten, noch leitende Stellen (Bahnhofsvorstände usw.) innehaben, während in anderen Behörden alle, auch überzeugte Gegner, aus dem Dienst entlassen wurden“. Vgl. LR Fürth an MilReg, 6. Dezember 1945, in: StA Nürnberg, LRA Fürth (1962), Nr. 40/1. Erst im Februar 1946 begann die Militärregierung "to reduce the tremendous backlog in these fields caused by previous directives which prevented the vetting of persons in these categories“. Hist. Rep., Det. für Ober- und Mittelfranken, 9. Februar 1946, in: NA, RG 260, 10/81-3/8.

90 RegPrās an bay. Staatsregierung, 19. November 1945, in: BayHStA, Reg von Mittelfranken, Berichterstattung 1945, AZ 1-64, Bd. 7. Die Massenentlassungen überstiegen zeitweise auch die Kräfte der SpecialBranch-Offiziere, die jeden einzelnen Fall überprüfen mußten, so daß sie sich anfangs nur um die „political incriminated persons in the higher brackets“ kümmern konnten. Vgl. Annual Hist. Rep., Det. Ansbach, 1. September 1946, in: NA, RG 260, 10/80-3/6. 
Reihe mitmarschiert waren. Die amerikanischen Maßnahmen betrafen aber auch Männer wie Friedrich Böhner, den Freimaurer Friedrich Wilhelm Beuschel oder Albert Aker, die - wie zahlreiche andere auch - schwerlich als Nationalsozialisten einzustufen waren. Gewiß, deutsch-national gesinnt, hatten sie sich 1933 mit der NSDAP arrangiert und sich dabei so weit korrumpieren lassen, daß ihr Berufsethos ebenso Schaden nahm wie ihre traditionellen Vorstellungen von Recht und Gerechtigkeit. Alle drei hatten im Frühjahr 1933 geschwiegen, als die sozialdemokratischen Stadträte mißhandelt und nach Dachau verschleppt worden waren. Keiner von den dreien hatte seine Stimme erhoben, als die Juden der Stadt nach der NS-Machtergreifung immer größerem Druck ausgesetzt gewesen und schließlich in der „Reichskristallnacht“ aus ihren Häusern geholt und in der Rezathalle zusammengetrieben worden waren ${ }^{91}$.

Andererseits konnte ihnen aber niemand den Vorwurf machen, sie hätten im Stadthaus den Parteigenossen herausgekehrt, Untergebene zum Eintritt in die Partei gedrängt, Parteigenossen bevorzugt oder sich selbst aufgrund ihrer Parteizugehörigkeit Vorteile verschafft. Böhner hatte sich - vor allem im Kirchenkampf - nicht gescheut, offen Kritik an der NSDAP zu üben. Alfred Hartmann, Jude und nach Kriegsende Generalkläger beim Kassationshof im bayerischen Staatsministerium für Sonderaufgaben, der Böhner persönlich gut kannte, schrieb über ihn: „Ich habe in ihm einen Mann von streng rechtlicher Denkweise und lauterster, hochanständiger Gesinnung kennengelernt, der durchaus unpolitisch eingestellt und vor allem frei von jedem radikalen Einschlag war. Auch nach seinem Beitritt zur NSDAP hat er mir ... unverminderte Achtung und Freundlichkeit bewiesen, auch in den Zeiten der schlimmsten Judenverfolgung.“92 Über Aker gab der sozialdemokratische Stadtrat Karl Stürzenhofekker zu Protokoll: „Wenn ich heute noch an die öfteren Aussprachen denke, die ich mit ihm hatte, dann kann ich nur sagen, daß sie für mich wie für ihn sehr gefährlich waren. Aktivistisch sowie propagandistisch ist er nie in Erscheinung getreten ..."93 Auf solche entlassene Beamte bezog sich auch der sozialdemokratische Oberbürgermeister Hans Schregle, als er in der ersten Sitzung des Beratenden Ausschusses der Stadt Ansbach in Anwesenheit führender amerikanischer Offiziere offen sein Bedauern über ihr Ausscheiden aussprach, das durch das „Machtgebot des Feindes“94 verursacht worden sei.

Die von zahlreichen Ungerechtigkeiten überschatteten Massenentlassungen, die mehr als der Hälfte aller vor der Besetzung beschäftigten Beamten, Angestellten und Arbeiter den Arbeitsplatz kosteten, bedeuteten einen beispiellosen Bruch mit den Traditionen des deutschen Berufsbeamtentums. Die personellen Veränderungen nach der Machtergreifung der NSDAP waren dagegen weit weniger einschneidend gewesen. Anders als 1933 bestand für die betroffenen Beamten und Angestellten 1945/46 zunächst auch kaum eine Möglichkeit, sich den neuen Verhältnissen durch Gesinnungsund Parteiwechsel anzupassen. In den ersten beiden Jahren nach dem Krieg blieb die ehemalige Mitgliedschaft in der NSDAP ein Makel, der sich nicht abschütteln ließ.

Auf deutscher Seite lösten die harten Maßnahmen der Militärregierung eine Welle von Protesten aus. Der Erzbischof von München und Freising, Michael von Faulhaber,

91 Vgl. Amtsgericht Ansbach, Registratur S: Nr. 5.

92 Ebenda: Nr. 4.

93 Ebenda: Nr. 6.

94 Prot. der Sitzung, in: Stadtverwaltung Ansbach, Registratur des OB. 
verfaßte zusammen mit dem Landesbischof der Evangelisch-Lutherischen Kirche in Bayern, Hans Meiser, ein energisches Protestschreiben an die Militärregierung, in dem sie die politische Säuberung heftig kritisierten. „Es müßte das Vertrauen zu einer geradlinigen Rechtspflege auf das schwerste erschüttern, wenn die einfache Zugebörigkeit zur Partei nach einem blinden Schema unterschiedslos mit so schwerer Strafe geahndet würde, wie es die plötzliche Entlassung aus Amt und Stelle ist. Wir sprechen allen rechtlich und human gesinnten Menschen aus der Seele, wenn wir fordern: Jeder Einzelfall muß persönlich behandelt werden. “95 Ministerpräsident Fritz Schäffer legte am 1. August 1945 ein Grundsatzmemorandum vor, das man auch in den höheren Stäben der Militärregierung zur Kenntnis nahm. Darin hieß es: Die Entnazifizierung lege ganze Verwaltungszweige lahm; die Belebung der Wirtschaft werde blockiert; die entlassenen Beamten könnten keine andere Arbeit finden, ihre Familien hungerten. Das Gefühl allgemeiner Hilflosigkeit breite sich aus ${ }^{96}$. Er schlug deshalb vor, alle leitenden Positionen mit untadeligen Personen zu besetzen, die „aktiven Nazis“ zu feuern und die nur ,formellen“ Pgs in ihren Stellungen zu belassen.

Regierungspräsident Reichard nahm ebenfalls kein Blatt vor den Mund. „Nominelle Parteimitgliedschaft", so heißt es in einer Aufzeichnung Dorns über ein Gespräch mit dem Regierungspräsidenten, „sei seines Erachtens das schlechteste von allen Kriterien für die Entfernung aus dem Amt. Er glaubt, daß jeder Fall für sich von einem Expertenkreis oder etwas Vergleichbarem gewürdigt werden sollte ... Ohne nominelle Pgs, die ansonsten zuverlässig seien, könne er niemals eine funktionierende Verwaltung für den Regierungsbezirk bilden. ${ }^{\text {“97 }}$ Als erfahrener Beamter erkannte Reichard die Ungerechtigkeiten gegenüber Einzelnen, die in den amerikanischen Maßnahmen oft steckten. Außerdem sperrte er sich gegen Entlassungen ohne rechtliche Grundlage; eingeschworen auf die Grundsätze des deutschen Beamtentums und blind für die politischen Erfordernisse der Stunde ging er aber häufig so weit, daß er im Endeffekt auch wirklich belastete Parteigenossen in Schutz nahm. Etwa wenn er zum Widerstand gegen die Anordnungen der Besatzungsmacht aufrief oder in der Besprechung mit den Oberbürgermeistern und Landräten am 30.Juli 1945 pauschal erklärte: „Die Rechte der Behördenangehörigen bleiben gewahrt, sie ruhen nur für die Dauer des Gewaltaktes. Um einen Beamten oder Angestellten auch im Rechtssinne aus seinem Amt zu entfernen, müßten die im deutschen Recht vorgeschriebenen Vorschriften und Formen beachtet werden, selbst wenn es sich wirklich um aktive Nationalsozialisten handle." 98

Die neuen Landräte und Oberbürgermeister stimmten mit Reichard im Grunde überein. Auch die sozialdemokratischen Amtschefs wollten mit einem derart radikalen Neuanfang im Beamtentum nichts zu tun haben. Hans Schmidt, zunächst stellvertretender, dann kommissarischer Oberbürgermeister von Fürth, bemühte sich so hartnäckig, Entlassungen zu verhindern oder rückgängig zu machen, daß ihm Cofer

95 Faulhaber und Meiser an MilReg, 20. Juli 1945, in: LKA Nürnberg, Bestand: Ev.-Luth. Landeskirchenrat, Z. III 264 (MilReg).

96 Vgl. Niethammer, Entnazifizierung, S. $176 \mathrm{f}$.

97 Walter L. Dorn an Harold and Chan, 17. Juni 1945, in: NA, RG 226, Europe-Africa Division, Records Relating to Outposts in Germany, Folder Title: Germany 3/1/45-26/6/45.

98 Besprechung des RegPräs mit OB und LR, 30. Juli 1945, Prot. in: StA Nürnberg, Reg von Mittelfranken (1978), Nr. 213. 
schließlich jegliche Intervention untersagte ${ }^{99}$. Ansbachs Oberbürgermeister Ernst Körner trat im Januar 1946 an die Militärregierung heran, hob hervor, daß weder für das Rechnungsjahr 1944/45 noch für 1945/46 ein Haushaltsplan ausgearbeitet worden sei, und bat, „zum Zwecke der Aufarbeitung der großen Rückbestände Herrn Beuschel in untergeordneter Angestelltenstellung ... beschäftigen zu dürfen “100. Körner, der auch später immer wieder ein gutes Wort für die Entlassenen einlegte, hatte vorher noch nie eine Behörde geleitet, ohne die Hilfe der alten eingearbeiteten Beamten glaubte er die neuen Aufgaben nicht meistern zu können. Außerdem fürchtete er als politischer Außenseiter in der überwiegend konservativen Stadt wohl auch, sich noch weiter ins Abseits zu begeben, wenn er den entsprechenden Einsatz für die alten Beamten vermissen ließ. Er war deshalb häufig zu Kompromissen bereit und setzte sich entgegen seiner Überzeugung auch für die Wiederverwendung von wirklich belasteten Beamten ein.

Bornkessel, der erfahrene Verwaltungsfachmann, brauchte im sozialdemokratischen Fürth solche Rücksichten nicht zu nehmen. Als politisch Verfolgter, der während der NS-Zeit zweimal verhaftet worden war, hatte er sich anfangs von jedem Beamten distanziert, „der einen braunen Fleck auf seiner Weste hatte“, wie sich einer seiner engsten Vertrauten erinnert ${ }^{101}$. Als aber die Entlassungen immer weitere Kreise zogen und „solche“ und „solche“ gleichermaßen betrafen, änderte er seine Haltung schnell. Jetzt weigerte auch er sich, die amerikanische Säuberungspolitik mitzutragen und versuchte, den alten Beamtenstamm - unabhängig von seiner NS-Vergangenheit - zusammenzuhalten.

Schmidt, Körner und Bornkessel drangen mit ihren Bitten und Anträgen, die sie meist mit dem Hinweis auf ein drohendes Chaos in der Verwaltung bekräftigten, jedoch selten durch. Whitaker, der Leiter der Militärregierung in Ansbach, stellte zwar einige zeitweilige Arbeitsgenehmigungen für belastete Beamte aus, im Grunde aber spottete er über die Argumente der Bürgermeister: „Roosevelt starb einige Wochen vor dem Kriegsende: er mußte ersetzt werden. Churchill schied aus - er mußte ersetzt werden! Sehen Sie, in diesem Punkte scheiden sich die Geister! Sie haben in Deutschland Beamte, die haben einem Wilhelm II. gedient! Sie haben im Weimarer System Dienst geleistet und sie haben auch Hitler die Treue gehalten, dafür haben wir kein Verständnis, das sind letztlich Beweise dafür, daß Deutschland zur Demokratie noch nicht fähig ist." ${ }^{102}$ Er blieb wohl auch deshalb meist hart, weil er den Eindruck gewonnen hatte, daß sich die Bürgermeister nur selten ernsthaft um Ersatz für die Entlassenen bemühten. Gerade der Ansbacher Oberbürgermeister konnte sich über mangelnde Bewerbungen nicht beklagen. Viele Flüchtlinge aus den überwiegend katholischen ehemaligen Sudetengebieten, die nach eigenem Bekunden schon im öffentlichen Dienst gearbeitet hatten, boten ihre Dienste an, wurden in aller Regel aber abgelehnt. Im protestantischen Ansbach, wo man schon auf die Ernennung des Katholiken Hans Schregle zum Oberbürgermeister gereizt reagiert hatte, befürchtete man eine weitere Überfremdung. Als Schregle aushilfsweise einige Katholiken anstellte, sahen

99 Schriftliche Mitteilung von Alfred Schmidt vom 10. November 1984.

${ }^{100}$ Vgl. Prot. der Stadtratssitzung vom 15. Januar 1946, in: Stadtverwaltung Ansbach, Registratur des OB.

${ }^{101}$ Schriftliche Mitteilung von Alfred Schmidt vom 10. November 1984.

${ }^{102}$ So gab Schregle im Beratenden Ausschuß der Stadt Ansbach die Worte Whitakers wieder. Niederschrift der Sitzung des Ausschusses vom 9. Oktober 1945, in: Stadtverwaltung Ansbach, Registratur des OB. 
manche dahinter eine „Generallinie“ der Staatsregierung in München mit dem angeblichen Ziel, Beamtenstellen in Bayern „möglichst mit katholischen Kräften zu besetzen“"103.

Anstatt Ersatzkräfte einzustellen, bedienten sich die Oberbürgermeister und Landräte lieber allerlei „Taschenspielertricks“ (Schregle), um ihr Stammpersonal zu halten $^{104}$. Der Fürther Landrat Hörndlein stellte einen Kreisinspektor (Pg seit 1935), den er auf Weisung der Militärregierung hatte entlassen müssen, wenig später wieder ein, führte ihn aber nicht in den Personallisten. Dem Hausmeister des Landratsamts $(\mathrm{Pg}$ seit 1933) mußte Hörndlein nach einigem Zögern zwar die Entlassungspapiere ausstellen, am selben Tag tauchte aber die Frau des Hausmeisters in der Personalliste auf $^{105}$. Der „Ehefrauen-Trick“ erfreute sich offenbar so großer Beliebtheit, daß auch die Regierung in München darauf aufmerksam wurde: „Da die Einstellung von Ehefrauen nicht mit Unrecht als Umgehung des Verbotes, die Entlassenen weiterhin zu beschäftigen, gedeutet werden könnte, sind derartige Bewerbungsversuche grundsätzlich abzulehnen. Dies gilt auch dann, wenn die Ehefrau selbst politisch völlig unbelastet ist." 106

„We talk tough, but we act soft“, „The Bavarian Scandal“ und „How the Nazis stay in “, so lauteten nur einige der Schlagzeilen ${ }^{107}$, mit denen die amerikanische Presse im Frühherbst 1945 ihre Leser auf die Verzögerungen bei der Entnazifizierung in Bayern aufmerksam machte. Diese stark übertriebenen Meldungen riefen in der amerikanischen Öffentlichkeit Erinnerungen an die hochgespielten Entnazifizierungspannen in Aachen vom Herbst 1944 wach und erhielten neue Nahrung, als sich General Patton, der wegen seiner Nachlässigkeit in der Entnazifizierung schon früher in das Kreuzfeuer der Kritik geraten war, in einer improvisierten Pressekonferenz in seinem Hauptquartier in Bad Tölz zu einem unglücklichen Vergleich der amerikanischen Parteien mit der NSDAP hinreißen ließ. Von einem Reporter befragt: „After all, General, didn't most ordinary Nazis join their Party in about the same way that Americans become Republicans or Democrats?", soll der alte Haudegen ebenso trocken wie blauäugig geantwortet haben: „Yes, that's about it." ${ }^{\text {108 }}$

Die Wogen gingen daraufhin noch höher und unterspülten schließlich auch die Stellung des bayerischen Ministerpräsidenten Fritz Schäffer, der wegen seiner wiederholten Kritik an den überzogenen amerikanischen Säuberungsmaßnahmen zur Symbolfigur des Widerstandes gegen die Entnazifizierung geworden war. Angesichts der aufgeregten Meldungen in der Presse war für die amerikanische Militärregierung schnelles Handeln oberstes Gebot. Für ein Umschwenken auf einen angemessenen Säuberungskurs, wie ihn auch viele in den Reihen der Amerikaner forderten, oder die gründliche Prüfung von Schäffers Argumenten war jetzt die denkbar ungünstigste Zeit. Als Eisenhower die „Wahrheit über die Schäffer-Regierung“ erfuhr, fragte er zor-

${ }^{103}$ Besprechung des RegPräs mit OB und LR, 30. Juli 1945, Prot. in: StA Nürnberg, Reg von Mittelfranken (1978), Nr. 213.

${ }^{104}$ So RegPräs Schregle in der Besprechung mit OB und LR, 10. Dezember 1945, Prot. in: StA Nürnberg, LRA Scheinfeld, Nr. 367.

${ }^{105}$ Nicht näher bezeichneter Bericht über das LRA Fürth, in: NA, RG 260, 9/124-2/34.

${ }^{106}$ Mitteilung des bay. Finanzministeriums, wiedergegeben auf einer Schulleitertagung in Fürth am 19. Juni 1946, in: Stadtverwaltung Fürth, EAP 210.

${ }^{107}$ Vgl. Lutz Niethammer, Zwischen Verwaltungstradition und politischen Parteien, S. $195 \mathrm{ff}$.

${ }^{108}$ Ebenda, S. 200. 
nig, „was zum Teufel“ die Amerikaner in Deutschland zu suchen hätten, wenn sie nicht für eine Säuberung der deutschen Regierung und Verwaltung sorgten, und befahl am 28. September 1945 die sofortige Entlassung Schäffers ${ }^{109}$. Zugleich mußten mehrere Minister, Staatssekretäre und leitende Beamte ihre Plätze räumen. Auch in der Provinz blieb das Beben in München nicht ohne Folgen. In Ober- und Mittelfranken wurden mehr als ein Dutzend Landräte und auch Regierungspräsident Reichard vom Dienst suspendiert, weil sie die Entnazifizierung verzögert oder blockiert hatten. Daß Reichard sich überhaupt so lange hatte halten können, kam einer kleinen Sensation gleich, denn seine Vorstellungen einer Säuberung waren mit den Anschauungen der Besatzungsmacht von Anfang an nicht in Einklang zu bringen gewesen ${ }^{110}$.

Die Entscheidung über seine Nachfolge lag im Herbst 1945 nicht mehr allein in den Händen der Militärregierung. So jedenfalls glaubte das neue bayerische Kabinett von Ministerpräsident Wilhelm Hoegner (SPD). Der selbstbewußte Emigrant und entschiedene NS-Gegner hielt es für selbstverständlich, daß die Militärregierung seinem Kabinett ein Mitspracherecht bei der Auswahl der Spitzenbeamten einräumte. Als er aus der Zeitung erfuhr, daß die Militärregierung ohne sein Wissen einen Nachfolger für Reichard ernannt hatte, war er außer sich. Es besänftigte ihn auch nicht, daß der neue Mann, der bisherige Ansbacher Oberbürgermeister Hans Schregle, aus den Reihen der eigenen Partei kam. Im Gegenteil: Gerade ein Sozialdemokrat mußte wissen, daß „ihn die Militärregierung nicht allein“ einsetzen dürfe. In der ersten Erregung beauftragte Hoegner Innenminister Josef Seifried, ein "geharnischtes Schreiben nach Ansbach zu schicken“ und Schregle das Gehalt zu sperren. Die lapidare Bemerkung seines Innenministers, er könne von sich aus nichts unternehmen, „wenn die lokalen Militärregierungen nicht zustimmten“, zwang Hoegner allerdings zu der schmerzlichen Einsicht, daß sein Spielraum geringer war, als er angenommen hatte. Man einigte sich deshalb darauf, mit Maßnahmen einstweilen noch zu warten, „da man sich hierdurch eine ganze Menge Konflikte sparen könne" "111.

Schregle schien für die Militärregierung der geeignete Mann zu sein. Er genoß nicht nur hohes Ansehen als NS-Gegner, sondern war auch - anders als Reichard - zu der Úberzeugung gelangt, daß eine weitere deutsche Obstruktion gegen die amerikanischen Säuberungsmaßnahmen politisch verfehlt sei. Bei der monatlichen Zusammenkunft mit den Landräten und Oberbürgermeistern seines Regierungsbezirks führte er sich gleich mit einem Paukenschlag ein: „Ich bin der Auffassung, daß alle jene Beamten, die sich irgendwann einmal zur Partei gestellt haben, abtreten müssen. Sie haben aus ihren bisherigen Amtsstellen zu verschwinden und zwar rücksichtslos ... Es gibt keinen Stichtag zur Zeit, nach dem eine Unterscheidung der Parteigenossen zu erfolgen hat. Auch die Nichtparteigenossen sind unter die Lupe zu nehmen ..." Selbst Pgs, deren Beschäftigung von der Militärregierung genehmigt worden war, sollten "nach und nach entfernt" werden ${ }^{12}$. Dieser Ton beunruhigte die Landräte und Oberbürgermeister, die bis dahin vom Regierungspräsidenten eher Beschwichtigungen gehört hatten. Der neue Mann, der als Ansbacher Oberbürgermeister mit Kritik an den ame-

${ }^{109}$ Ebenda, S. $205 \mathrm{ff}$.

${ }^{110}$ Vgl. Hist. Rep., Det. für Ober- und Mittelfranken, September 1945, in: NA, RG 260, 10/81-3/8.

11 Bayerischer Ministerrat, 24. Oktober 1945, in: IfZ-Archiv, ED 120/354.

${ }^{112}$ Besprechung des RegPräs mit OB und LR, 29. Oktober 1945, Prot. in: StA Nürnberg, LRA Scheinfeld, Nr. 367. 
rikanischen Anweisungen selber nicht gespart hatte, war anscheinend päpstlicher als der Papst geworden, wie Nürnbergs Oberbürgermeister meinte: „Die Amerikaner sind bei weitem nicht so streng mit der Entnazifizierung wie wir selbst. Das Wohl des Volkes steht doch noch vor der Entnazifizierung. “113

Schregle hatte gute Gründe für seinen säuberungspolitischen Tatendrang. Die Offiziere der Militärregierung ließen bei seiner Amtseinführung keinen Zweifel daran, daß der bisherige Verzögerungs- und Obstruktionskurs nicht mehr länger hingenommen werde. Zugleich verwiesen sie auf die USFET-Direktive vom 5.Oktober 1945, in der es hieß: „At the earliest possible date and not later than 31 december, 1945, Military Government authority over German authorities will be exercised at the level of the state Government and all instructions to German authorities from Military Government authorities will be through the Minister President and the functional ministers of their respective state. ${ }^{.114}$ Diese Direktive, deren Erlaß angesichts des massiven Personalabbaus der amerikanischen Truppen im Sommer/Herbst 1945 unumgänglich geworden war, werde aber nur in die Tat umgesetzt, wenn, so bedeutete man Schregle, die Deutschen endlich ernst machten mit der Entnazifizierung. Schregle, der die Aussicht auf den „Wiedergewinn der Autonomie" nicht gefährden wollte, war deshalb sogar bereit, zeitweise übertriebene Säuberungsmaßnahmen in Kauf zu nehmen. Auf dem „Weg zum Wiedergewinn der Autonomie“ sei „die Entfernung nationalsozialistischer Mitarbeiter aus unseren Ämtern" unabdingbar, so Schregle gegenüber den Landräten und Oberbürgermeistern. „Wir müssen beweisen, daß wir uns auch ohne $\mathrm{Pg}$ zu verwalten wissen.“ ${ }^{115}$ Je höher das „Tempo in der Denazifizierung“, fuhr er fort, desto eher „werden wir Herr über uns selbst, werden wir wieder in den Besitz unserer Verwaltungshoheit gelangen ${ }^{116}$. In bayerischen Regierungskreisen fand sein Vorschlag einer säuberungspolitischen Roßkur kaum Beifall. Selbst Hoegner, der sich in Entnazifizierungsfragen nicht leicht zu Zugeständnissen bereit fand, empfahl Schregle Ende November 1945, seinen „Radikalismus vorläufig etwas dosiert anzuwenden “117.

Die strenge Zügelführung Schregles erfüllte ihren Zweck. Sie hielt die Amtschefs zu erhöhten Säuberungsanstrengungen an und erleichterte es so der Militärregierung, an ihrem Fahrplan festzuhalten: Am 15. November 1945 wurde die Verwaltung der Städte und Landkreise und am 15. Dezember 1945 die Verwaltung der Regierungsbezirke auf deutsche Behörden übertragen ${ }^{118}$. Künftig wollte die Besatzungsmacht den unteren und mittleren Verwaltungsinstanzen völlig freie Hand lassen und sie, wie in der USFET-Direktive vom 5.Oktober angekündigt, nur noch indirekt über die Länderregierungen beaufsichtigen. Dies war der „Anfang vom Ende“, kommentierte die Militärregierung von Ober- und Mittelfranken etwas wehmütig ${ }^{119}$. Einigen Offizieren fiel der Abschied von der Macht tatsächlich schwer. Sie bedauerten es, daß ihnen nun

\footnotetext{
113 Ebenda.

114 James K. Pollock u. a., Germany under Occupation, Ann Arbor 1949, S. 145.

115 Besprechung des RegPräs mit OB und LR, 29. Oktober 1945, Prot. in: StA Nürnberg, LRA Scheinfeld, Nr. 367.

116 Ebenda.

117 So berichtete Schregle am 10. Dezember 1945 den OB und LR über ein Telefonat mit Hoegner, Prot. in: StA Nürnberg, LRA Scheinfeld, Nr. 367

${ }^{118}$ Vgl. Anm. 114. Vgl. dazu auch Hist. Rep., Det. für Ober- und Mittelfranken, Dezember 1945, in: NA, RG 260, 10/81-3/8.

${ }^{119}$ Hist. Rep., Det. für Ober- und Mittelfranken, Dezember 1945, in: Ebenda.
} 
„das Recht genommen“ wurde, „Befehle zu erlassen“"120. Andere hielten die Zeit noch nicht für reif und zweifelten an der Fähigkeit der Deutschen, „allein zu denken, d.h. Entscheidungen zu treffen und Tätigkeiten zu überwachen ohne genaue Anweisungen "121. Außerdem bereitete es manchen Militärregierungsdetachments Schwierigkeiten, ihren eigenen Apparat der neuen Lage anzupassen, die weniger eine energische Hand als Fingerspitzengefühl erforderte. Sie machten so noch einige Zeit im alten Stil weiter und berichteten, daß es "keine Reduzierung des Umfangs ihrer Arbeit“ gegeben habe und daß der "Übergang mit dem damit verbundenen Personalrückgang" nichts anderes bedeute, als daß weniger Leute die gleiche Arbeit wie früher täten ${ }^{122}$. Ihre "große" Zeit aber war vorbei, nach einigen Wochen forderte auch hier der Personalmangel seinen Tribut.

Die meisten Militärregierungsoffiziere aber begrüßten die Politik des „Turn it over to the Germans". Sie zogen sich bereitwillig aus der praktischen Arbeit zurück und beschränkten sich auf Beraterfunktionen. „Ich kannte eine große Anzahl Offiziere“, schrieb Dorn in seinen Erinnerungen, ,und unter ihnen erinnere ich mich noch besonders lebhaft an Oberst Whitaker in Ansbach in Nordbayern, denen es gelang, ihre Regierungspräsidenten, Bürgermeister und Landrat nach der Konsolidierung ihrer Behörden wirklich zu beraten und eine weit wichtigere Funktion auszuüben, nachdem sie keine Befehle mehr erlassen konnten. Nun wuchsen sie in die Aufgabe hinein, die Deutschen durch moralische Überzeugungskraft dafür zu gewinnen, bestimmte Dinge zu tun ... ${ }^{\alpha 23}$ Steward Hillard, Cofers Nachfolger in Fürth, traf sich häufig zu einer Tasse Kaffee mit Oberbürgermeister Bornkessel im Fürther Rathaus, der später zu Hillards Abschied sagte: „... es habe kaum ein menschliches und kommunales Thema gegeben, das in den fast alltäglichen Diskussionen in der beliebten "Kaffeestunde nicht eingehend behandelt wurde. " ${ }^{124}$ Regierungspräsident Schregle konnte seit der Jahreswende 1945/46 sogar an den regelmäßigen Treffen der Chefs der amerikanischen Militärregierung in Ober- und Mittelfranken teilnehmen und so unmittelbar mit den amerikanischen Vorstellungen vertraut werden. Er stellte dabei fest, daß „weitaus die überwiegende Mehrzahl aller Amerikaner ... von dem festen Willen beseelt ist, uns Deutschen zu helfen, und zwar in dem Maße mehr, als sie zu unterscheiden gelernt haben zwischen den Nationalsozialisten und den Millionen anständiger Deutscher"125.

Immer öfter ergaben sich nun auch private Kontakte zwischen den amerikanischen Offizieren und den deutschen Honoratioren. Col. Whitaker, der mittlerweile seine Frau und seine beiden Kinder nach Ansbach hatte nachkommen lassen, lud Oberbürgermeister Körner und Landrat Neff zu sich in die beschlagnahmte Lingmann-Villa ein $^{126}$. Man aß, trank und plauderte miteinander, lernte sich besser kennen, und die anfängliche Befangenheit löste sich schnell. Damit waren die Schwierigkeiten im Umgang miteinander gewiß noch längst nicht ausgeräumt. Die Militärregierung war aber

\footnotetext{
${ }^{120}$ Dorn, Inspektionsreisen, S. 55.

${ }^{121}$ Hist. Rep., Det. für Ober- und Mittelfranken, Dezember 1945, in: NA, RG 260, 10/81-3/8.

122 Ebenda.

${ }^{123}$ Dorn, Inspektionsreisen, S. 55.

124 Fürther Nachrichten vom 2. März 1949.

${ }^{125}$ Besprechung des RegPräs mit OB und LR, 6. Mai 1946, Prot. in: StA Nürnberg, LRA Scheinfeld, Nr. 367.

${ }^{126}$ Mündliche Mitteilung von Ernst Körner jr. vom 28. November 1983.
} 
nicht mehr die unberechenbare, allmächtige Instanz, als die sie kurz nach dem Einmarsch erschienen war ${ }^{127}$.

Etwa zur gleichen Zeit, als die Auseinandersetzungen zwischen der Militärregierung und den deutschen Verwaltungschefs über die Massenentlassungen dem Höhepunkt zusteuerten, kam es auch innerhalb der amerikanischen Besatzungsmacht auf allen Ebenen zu Konflikten über einen angemessenen Säuberungskurs. Man könne nicht „Eisenbahnen mit Ladengehilfen betreiben und die Fabriken von Schuhputzern leiten lassen“, meinten die Anhänger einer eher pragmatisch-konservativen Linie in der Militärregierung, die sich für eine baldige Wende in der Säuberungspolitik einsetzten, während die Entnazifizierungsabteilung, Angehörige der Erziehungsabteilung und die überwiegend linksstehenden Investigatoren der Psychological Warfare Division eine Intensivierung der Säuberung forderten ${ }^{128}$. Hauptkonkurrenten waren in Fürth das Militärregierungsdetachment des pragmatischen Cofer und das CIC, das als Abschirmdienst der amerikanischen Streitkräfte natürlich vor allem die Sicherheit der eigenen Truppen im Auge hatte, und, überspitzt formuliert, in jedem Parteigenossen eine potentielle Gefahr witterte ${ }^{129}$.

Lieutenant Thomas K. Hodges, der Chef des Fürther CIC, ermittelte im Sommer 1945 gegen ein junges Fräulein, das seit April 1945 im Büro von Captain Cofer arbeitete. Als britische Staatsbürgerin, die sich bei Kriegsende in Deutschland aufgehalten hatte und nicht interniert gewesen war, galt sie automatisch als Verdachtsperson. Das Fräulein hieß Mary Morton ${ }^{130}$; sie war 1911 in Belfast geboren worden und stammte aus einer angesehenen britischen Familie, die in den zwanziger Jahren nach Leningrad umgezogen war. Als die deutsche Wehrmacht im Sommer 1941 den Feldzug gegen Rußland begann, wurde die mittlerweile mit einem Offizier der Roten Armee verheiratete Mary in den Kaukasus evakuiert, dort von Wehrmachtseinheiten aufgegriffen und nach einer längeren Odyssee durch halb Europa nach Nürnberg gebracht. Hier bekam es Mary mit der Gestapo zu tun. Sie stand in dem - unbegründeten - Verdacht für den britischen Geheimdienst zu arbeiten.

Die Nachforschungen von Hodges waren zunächst nichts weiter als eine Routineprüfung. Zur selben Zeit machte aber in den Reihen von CIC ein Bericht über zwei im Raum Fürth tätige Gestapo-Agentinnen die Runde, der offenbar auch auf dem Schreibtisch von Hodges landete. Eine der gesuchten Personen mochte gewisse Ähnlichkeiten mit Fräulein Morton haben, die gleich doppelt verdächtig erschien, als sich herausstellte, daß sie ein russisches Mädchen zur Freundin hatte. Was lag näher, als in ihr die zweite Agentin zu sehen, zumal sie mit Vornamen Natalie hieß, ein Name, der nach den Erkenntnissen des amerikanischen Abschirmdienstes von Gestapo-Agentinnen häufig benutzt wurde. CIC hegte also den ungeheuerlichen Verdacht, der Leiter der Fürther Militärregierung beschäftige eine ehemalige Agentin der Gestapo als Schreibkraft. Ein Eingreifen des militärischen Abschirmdienstes schien dringend geboten.

\footnotetext{
${ }^{127} \mathrm{Vgl}$. Anm. 53.

${ }^{128} \mathrm{Vgl}$. Niethammer, Entnazifizierung, S. $232 \mathrm{f}$.

${ }^{129}$ Zum CIC allgemein vgl. History of the Counter Intelligence Corps, in: US Army Intelligence and Security Command, Fort George G. Meade, Maryland.

${ }^{130}$ Alle Belege für den Fall Miss Mary Morton, in: NA, RG 260, 9/122-5/13.
} 
Die Untersuchung durch einen fähigen Agenten erbrachte wenig Konkretes, erregte umso mehr aber den Unwillen Cofers. Der Chef der Fürther Militärregierung, selbstbewußt und ein Mann mit Augenmaß, erblickte in den Nachforschungen, die das CIC hinter seinem Rücken anstellte, eine Untergrabung seiner Autorität. Außerdem zweifelte Cofer schon seit längerem an den Fähigkeiten von Hodges und seiner CICEinheit, die nicht immer mit der gebotenen Sorgfalt arbeitete. Er drohte sogar, seinerseits gegen das CIC vorzugehen, wenn sich der Geheimdienst länger in seine Angelegenheiten mische. „Ich war nicht gewillt“, so Cofer, „dem CIC zu erlauben, die Art und Weise meiner Amtsführung zu bestimmen." Der CIC-Agent stellte daraufhin die Untersuchung ein. Wenig später wurde die wahre Gestapo-Agentin in Bamberg aufgegriffen. Fräulein Morton war somit von jedem Verdacht befreit. Der Sturm im Wasserglas hätte sich legen können, aber das Gegenteil geschah.

Lt. Hodges fertigte im September 1945 einen Bericht über den Stand der Entnazifizierung an, in dem die unterschiedlichen Auffassungen über den richtigen Säuberungskurs deutlich zum Ausdruck kamen. Captain Cofer, so lautete die Quintessenz des Berichts, verhindere in seinem Wirkungsgebiet eine gründliche Entnazifizierung und halte sogar an einem Mann als Oberbürgermeister fest - gemeint war Schwiening - der, „vom politischen Standpunkt aus unzuverlässig“, wegen seiner früheren NSDAP-Zugehörigkeit Gegenstand erheblicher Mißstimmung in Fürth sei. Außerdem beklagte sich Hodges darüber, daß Cofer eine gedeihliche Zusammenarbeit von Militärregierung und CIC systematisch boykottiere. Zum Beweis dafür wärmte er den Fall Morton wieder auf. Angesichts dieser schweren Vorwürfe wurde nun auch die Militärregierung in München hellhörig. Sie schien daran zu zweifeln, ob der dubiose Fall Morton tatsächlich geklärt war. Colonel Roy L. Dalferes, als G-5 Offizier der 3. Armee damals auch interimistischer Leiter der Militärregierung in Bayern, beauftragte deshalb am 19. Oktober 1945 Colonel Haight von der Militärregierung in Mittel- und Oberfranken mit einer erneuten Untersuchung des Falles Morton, der längst zum Fall Cofer geworden war. „Es wird gewünscht“, so hieß es in der Anweisung von Dalferes, „daß Sie eine Untersuchung über die Entnazifizierung in Fürth vornehmen ... Aus CIC-Berichten geht eindeutig hervor, daß zwischen dem CIC und der Militärregierung diesbezüglich nicht die besten Beziehungen bestehen ... Da Captain Cofer und nicht CIC die Verantwortung für die Entnazifizierung trägt, ist es einleuchtend, daß Captain Cofer Nachforschungen und Empfehlungen des CIC nicht begrüßt. Er ist sogar soweit gegangen, CIC-Offizieren und -Agenten Kriegsgerichtsverfahren anzudrohen."Außerdem sollte Haight dem Chef der Fürther Militärregierung zu verstehen geben, daß er allein für die Entnazifizierung verantwortlich sei, man aber von ihm erwarte, „mit dem CIC bei dessen Tätigkeit engstens zusammenzuarbeiten“.

Haight schickte sofort einen Public-Safety-Offizier, Major Garret Houman, nach Fürth, der schon am 1. November 1945 einen detaillierten Bericht vorlegte. Die Vorwürfe, die aus den Reihen des CIC gegen Cofer erhoben worden waren, erwiesen sich als unbegründet. Von einer Verzögerung der Entnazifizierung in Fürth könne keine Rede sein: „Die Direktiven werden streng gehandhabt ... Die Säuberungsarbeit in der Gegend ist weit fortgeschritten und gut gemacht worden.“ Zum Vorwurf, Cofer halte einen Mann mit NS-Vergangenheit als Oberbürgermeister, habe sich nichts ergeben, was nicht schon bei der Einsetzung von Schwiening, dem auch nun wieder von allen Seiten seine antinazistische Gesinnung bescheinigt werde, bekannt gewesen sei; auch 
die neuerliche Untersuchung des vor Monaten schon zu den Akten gelegten Falls Morton habe keine neuen Aufschlüsse erbracht.

Major Haight leitete den Bericht von Major Houman an den mittlerweile amtierenden Direktor der Militärregierung von Bayern, General Walter J. Muller, mit der Bemerkung weiter: „Meiner Ansicht nach ergibt sich aus dem Untersuchungsbericht kein Grund für irgendeine Aktion gegen Captain Cofer." Muller wollte dem gerne zustimmen, merkte in seiner Antwort vom 15. Dezember 1945 aber an: „Es ist jedoch offensichtlich, daß Captain Cofer es versäumt, vom CIC vollen Gebrauch zu machen ... Es wird angeordnet, daß der Entnazifizierung in Fürth besondere Aufmerksamkeit geschenkt und ein formloser Bericht angefertigt wird, dessen Ergebnis mir vorgelegt werden muß."

Noch vor Weihnachten 1945 wurde der Anweisung Mullers entsprochen und ein kurzer Bericht angefertigt, in dem es wieder hieß, daß sich das Fürther Detachment in Sachen Entnazifizierung nichts vorzuwerfen habe. Das CIC, dessen Stern allgemein zu sinken begann, als sich auch in den obersten Stäben der Militärregierung die Erkenntnis durchsetzte, daß von deutscher Seite wenig für die Sicherheit der amerikanischen Streitkräfte zu befürchten war, mußte in Fürth zurückstecken. Cofer aber hatte sich in der harten Auseinandersetzung behaupten können und gewann nun wieder einiges von jenem Spielraum zurück, der nach dem Erlaß der Juli-Direktive fast ganz verlorengegangen war.

\section{3. „Renazifizierung“ des öffentlichen Dienstes 1947/48?}

Die Entlassungswelle vom Sommer und Herbst 1945 hatte in Ansbach u.a. die Spitzenbeamten Friedrich Böhner, Friedrich Wilhelm Beuschel und Albert Aker getroffen. Jeder von ihnen wies den Vorwurf, Nationalsozialist gewesen zu sein, weit von sich. Der frühere Freimaurer Beuschel empfand es als eine ,unerträgliche seelische Belastung“, als ihn die Spruchkammer im Februar 1947 in die Gruppe IV der sogenannten Mitläufer einreihte. Als Mitläufer, so argumentierte er, werde er in „einen Topf mit jenen“ geworfen, die „mich als Gegner betrachten mußten und die nicht wie ich in den vergangenen zwölf Jahren immer damit rechnen mußten, schon am nächsten Tage ihres Dienstes enthoben zu sein ${ }^{\text {“131 }}$. Nach seiner Einschätzung hatten er und seine beiden Kollegen während der NS-Zeit lediglich ihre Pflicht getan. Einer Mitverantwortung für das NS-Regime und seiner schlimmen Hinterlassenschaft war sich keiner bewußt, sie nahmen im Gegenteil für sich in Anspruch, die von oben kommenden Anordnungen in vielen Fällen abgemildert zu haben. Den "geringen Einfluß", den ihm seine Parteimitgliedschaft gewährt habe, so schrieb Böhner 1946, habe er „ausschließlich zum Nutzen der Stadt und ihrer Einwohner“"132 geltend gemacht.

Der Verlust ihrer Stellung und ihrer Dienstbezüge nach jahrzehntelanger Tätigkeit war für viele Betroffene ideell und psychisch schwerer zu ertragen als materiell. Albert Aker z. B. war ein vermögender Mann. Er widmete sich während seiner „Arbeitslosigkeit" dem Wiederaufbau des im Besitz der Aker'schen Erbengemeinschaft befindli-

${ }^{131}$ Beuschel an Spruchkammer Ansbach-Stadt, 26. Februar 1947, in: Amtsgericht Ansbach, Registratur S: Nr. 5.

132 Böhner an Spruchkammer Ansbach-Stadt, 10. Dezember 1946, in: Ebenda: Nr. 4. 
chen Anwesens in der Bahnhofstraße, das bei den Luftangriffen vom 22./23. Februar 1945 beschädigt worden war. Außerdem verrichtete er leichtere Arbeiten für das katholische Pfarramt ${ }^{133}$. Der ebenfalls entlassene Florian Groganz (Pg seit 1933), der frühere stellvertretende Stadtbaurat, arbeitete nun vorübergehend als Hilfsarbeiter im Stadtbauamt - seiner alten Behörde also, dürfte dabei aber kaum zu Schaufel und Spitzhacke gegriffen haben ${ }^{134}$. Sein gleichfalls dispensierter ehemaliger Vorgesetzter Willy Flach (Pg seit 1933) wußte seine in der Stadtverwaltung erworbenen Bauplankenntnisse unternehmerisch umzusetzen, indem er ein Architekturbüro leitete ${ }^{135}$. Der 60 jährige Friedrich Böhner dagegen, vielleicht der Couragierteste unter den höheren Beamten der Ansbacher Stadtverwaltung, mußte als Hilfsarbeiter einer Baufirma schwere körperliche Arbeit leisten ${ }^{136}$.

Gleichwohl konnte auch er sicher sein, nach wie vor zur Ansbacher Beamtenschaft gezählt zu werden. Geächtet war keiner der Entlassenen; das zeigte sich an den Bemühungen des Stadtrats um ihre Wiedereinstellung und noch mehr im Umgang mit den alten Kollegen, von denen sie wie Beamte auf Kur oder im Krankenstand behandelt wurden. Auch in der Öffentlichkeit genossen die Entlassenen weiterhin kaum vermindertes Ansehen, und selbst die Regierung von Ober- und Mittelfranken stärkte ihnen den Rücken ${ }^{137}$. Regierungspräsident Reichard richtete sogar eine Betreuungsstelle für die entlassenen Beamten und Angestellten ein, deren Aufgabe es war, Hilfesuchenden eine geeignete Beschäftigung zu vermitteln. „Sie werden gebeten“, so appellierte der Regierungspräsident an die Landräte und Oberbürgermeister, „alles zu tun, um das Los der Stellensuchenden " zu erleichtern ${ }^{138}$.

Unterdessen debattierte der Ansbacher Stadtrat fast in jeder Sitzung über Wege zur Wiedereinstellung der Entlassenen. Als im Sommer 1946 die Spruchkammer ihre Arbeit aufnahm, wurde sie bestürmt, die Verfahren der höheren Beamten bevorzugt zu behandeln. Ende 1946 hatten diese Bemühungen erstmals Erfolg, als der Verwaltungsinspektor Martin Winkler, der von der Spruchkammer das Prädikat „nicht betroffen“ erhielt, in seine frühere Position zurückkehren konnte ${ }^{139}$. Im Frühjahr 1948 war die alte Garde bis auf den ehemaligen Oberbürgermeister und Kreisleiter Richard Hänel, der noch im Interniertenlager saß, und seinen früheren Stellvertreter Albert Böhm wieder komplett. Beuschel, von der Spruchkammer ebenfalls als "nicht betroffen“ eingestuft, kehrte im Februar 1948 als städtischer Verwaltungsdirektor in das Stadthaus zurück $^{140}$. Aker, dessen Spruchkammerverfahren mit der Einstufung als Mitläufer endete, wurde im März 1948 zunächst als Angestellter, dann im April als Beamter wieder angestellt. Ihm unterstand mit der Dienststelle 12 das gesamte Gewerbewesen ${ }^{141}$. Böhner, der aus dem Spruchkammerverfahren als Entlasteter hervorging, erhielt vor Weihnachten 1947 die Ernennung zum berufsmäßigen Stadtrat, und zweieinhalb

\footnotetext{
133 Ebenda: Nr. 6.

134 Ebenda: Nr. 7.

135 Ebenda: Nr. 8.

136 Ebenda: Nr. 4.

${ }^{137}$ Besprechung des RegPräs mit OB und LR, 30. Juli 1945, Prot. in: StA Nürnberg, Reg von Mittelfranken (1978), Nr. 213.

138 Besprechung des RegPräs mit OB und LR, 27. August 1945, Prot. in: Ebenda.

${ }^{139}$ Vgl. dazu die Prot. der Stadtratssitzungen vom 17. September, 8. Oktober, 5. November und 20. Dezember 1946, in: Stadtverwaltung Ansbach, Registratur des OB.

${ }^{140} \mathrm{Vgl}$. dazu das Prot. der Stadtratssitzung vom 2. Februar 1948, in: Ebenda.

${ }^{141}$ Vgl. dazu die Prot. der Stadtratssitzungen vom 15. März und 26. April 1948, in: Ebenda.
} 
Jahre später, im Juli 1950, löste er Ernst Körner als Oberbürgermeister von Ansbach $a b^{142}$.

Die Betroffenen selbst und die Ansbacher Bevölkerung erblickten in der Rehabilitierung nach zwei-, dreijährigem Berufsverbot einen Akt der Wiedergutmachung des im Zuge der amerikanischen Massenentlassungen 1945 entstandenen Unrechts. Die Tendenz, die damaligen Ungerechtigkeiten aus der Welt zu schaffen, kam freilich nicht nur Böhner und Aker zugute, von ihr profitierten bald auch zahlreiche Beamte und Angestellte, die mehr als nur nominelle Pgs gewesen waren. Sie drangen allerdings nur in den unteren und mittleren Dienst der Ansbacher Stadtverwaltung ein, leitende Positionen blieben ihnen verschlossen.

Die Rückkehr ehemaliger Parteigenossen in den öffentlichen Dienst ließ sich ab Ende 1946 in ganz Bayern beobachten. „Die Türen der Ämter“ wurden, wie Regierungspräsident Schregle prophezeit hatte, „weit aufgerissen “143. Durch sie ergoß sich eine Flut von Mitläufern. Um die Jahreswende 1946/47 betrug der Anteil der ehemaligen Pgs in leitenden Positionen im Regierungsbezirk Ober- und Mittelfranken bereits wieder etwa 35 Prozent $^{144}$; ein Jahr zuvor war er noch verschwindend gering gewesen. Die Wiedereinstellungspraxis der Oberbürgermeister und Landräte stand dabei, zumindest bis zum Frühjahr 1947, im scharfen Gegensatz zur offiziellen Politik der bayerischen Regierung. Die Anordnungen von oben wurden, so Regierungspräsident Schregle, „mißachtet oder in einem Umfange dagegen verstoßen ... daß man geneigt ist, hier von einer merkwürdigen Unbotmäßigkeit von Beamten zu sprechen“145. Erst im März 1947 gab auch die bayerische Regierung grünes Licht für die Wiederverwendung ehemaliger Pgs im öffentlichen Dienst, sofern deren Spruchkammerurteil rechtskräftig war, die Zustimmung der amerikanischen Militärregierung vorlag und der Betreffende die „Gewähr dafür bietet, daß er am Ausbau und der Sicherung dauernder Grundlagen eines demokratischen Staatslebens positiv mitwirken wird“ ${ }^{146}$.

Zwei, drei Jahre nach dem Erlaß der USFET-Direktive vom 7.Juli 1945 war der revolutionäre Bruch mit den Traditionen des deutschen Berufsbeamtentums gleichsam wieder ,geheilt“. Alles beim alten also? Gaben nun tatsächlich wieder Nationalsozialisten in den Ämtern den Ton an, wie es im zeitgenössischen Schlagwort von der „Renazifizierung“ des öffentlichen Dienstes mitschwingt? Einer, der dies behauptete, war Regierungspräsident Schregle. Gegenüber der amerikanischen Intelligence Division äußerte er im August 1949: ,Ja, ich bin der Ansicht, daß sich in Bayern eine Renazifizierung des öffentlichen Lebens bemerkbar macht ... Die Tatsache, daß mehr und mehr ehemalige Nazis in ihre früheren Stellungen zurückgekehrt sind, birgt an sich schon die Gefahr des Wiedererwachens alter Nazi-Instinkte in sich. Sie fühlen sich ge-

\footnotetext{
142 Vgl. dazu die Prot. der Stadtratssitzungen vom 9. und 23. Dezember 1947, in: Ebenda. Vgl. auch Fränkische Landeszeitung vom 19. Juli 1950.

${ }^{143}$ Besprechung des RegPräs mit OB und LR, 20. März 1947, Prot. in: StA Nürnberg, Reg von Mittelfranken (1978, Zusatz), Nr. 25.

${ }^{144}$ Ebenda.

145 Besprechung des RegPräs mit OB und LR, 20. März 1947, Prot. in: StA Nürnberg, Reg von Mittelfranken (1978, Zusatz), Nr. 25.

${ }^{146}$ Vgl. die am 18. März 1947 veröffentlichte Verordnung Nr. 113 zur Regelung der Rechtsverhältnisse der vom Gesetz zur Befreiung von Nationalsozialismus und Militarismus betroffenen Beamten vom 29. Januar 1947, in: BGVBI. 7/1947. Siehe auch die Ausführungen Schregles in der Besprechung des RegPräs mit OB und LR vom 20. März 1947, Prot. in: StA Nürnberg, Reg von Mittelfranken (1978, Zusatz), Nr. 25.
} 
wissermaßen rehabilitiert, was gleichbedeutend damit ist, daß sie letzten Endes doch Recht behalten haben." ${ }^{\text {"147 }}$

Schregle stand mit dieser Meinung nicht allein. Viele Sozialdemokraten, Kommunisten, Verfolgte des NS-Regimes und Liberale, die häufig selbst bei der Rehabilitierung vieler kleiner Pgs mitgeholfen hatten, nun aber einsehen mußten, daß sie möglicherweise zuviele Kompromisse geschlossen hatten und damit auch die politische Atmosphäre in den Städten und Dörfern zu ihren Ungunsten beeinflußt hatten, klagten 1948/49 heftig über eine Renazifizierung des öffentlichen Lebens. „Man muß sich nur einmal in ein Auto setzen und von Amt zu Amt fahren, dann sieht man die verhängnisvolle Personalpolitik, die in der ganzen Beamtenschaft getrieben wird“, meinte etwa der Coburger Landtagsabgeordnete Georg Schneider (FDP). „Unbelastete werden gar nicht oder nur sehr zögernd befördert. Die Nazis, die es durch irgendwelche Mittel fertiggebracht haben, durch die defekte Entnazifizierungsmaschinerie zu rutschen, spielen sich gegenseitig die Bälle zu. “148

$\mathrm{Zu}$ einer wesentlich differenzierteren Beurteilung des Problems der Renazifizierung kam ein amerikanischer Militärregierungsoffizier in Dinkelsbühl, der sehr genau wußte, daß die vielen kleinen Parteigenossen vom Typ eines Böhner, Aker oder Beuschel wohl kaum als Nationalsozialisten zu bezeichnen waren. Wenn man annehme, „daß jeder, der Parteimitglied war, als ein ehemaliger Nationalsozialist betrachtet werden muß", dann könne man tatsächlich von einer Art Renazifizierung sprechen. Aber, so gab er in seinem Bericht an das Hauptquartier der bayerischen Militärregierung zu bedenken, „wenn wir nur diejenigen als ehemalige Nationalsozialisten betrachten, die früher führende Positionen in der NSDAP und den ihr angeschlossenen Organisationen innehatten“, dann werde man erkennen, daß nur ganz wenige „real Nazis"149 in ihre früheren Positionen zurückgekehrt seien. „Die alten Beamten sind zurück“, hielt auch Professor Dorn im März 1949 in seinen Aufzeichnungen fest, „aber jedermann versichert mir, daß Schwerbelastete, Belastete und Minderbelastete nicht darunter seien. “ ${ }^{150}$

Und schließlich, so wird man den, wie das Beispiel der Ansbacher Stadtverwaltung zeigt, zutreffenden Feststellungen Dorns, noch hinzufügen müssen, wurden in der zweiten Hälfte der Besatzungszeit nicht alle Ergebnisse der amerikanischen Säuberungs- und Personalpolitik rückgängig gemacht. Gewiß, die entlassenen Beamten und Angestellten strömten wieder zurück, aber zu einem Comeback großen Stils von Bürgermeistern, Landräten und Ratsherren aus dem Lager der NSDAP kam es nicht. In einer Untersuchung der Intelligence Division, die von der bayerischen Militärregierung nach den Kommunalwahlen von 1948 in Auftrag gegeben worden war, hieß es: „Ehemalige Mitglieder der NSDAP haben jetzt zwischen 10 und 30 Prozent der ,key local elective posts' in allen Kreisen des Landes inne. In den einflußreichen Kreistagen halten ehemalige Pgs nun zwischen 15 und 30 Prozent der Sitze ... In den Stadträten ... stellen NSDAP-Mitglieder zwischen 20 und 40 Prozent der Ratsherren ... Und von

\footnotetext{
${ }^{147}$ ID-Research Branch, Nümberg, Munich Brief, No. 162: Renazifizierung, 8. August 1949, in: NA, RG 260, 10/70-2/8.

${ }^{148}$ Stellungnahme von Schneider, in: Ebenda.

${ }^{149}$ FOD Dinkelsbühl an OMGB, Intelligence Division, 15. September 1948, in: NA, RG 260, 9/143-1/6.

${ }^{150}$ Dorn, Inspektionsreisen, S. 143.
} 
den Bürgermeistern in den tausenden kleinen ländlichen Gemeinden Bayerns sind zwischen 10 und 25 Prozent ehemalige Pgs. “151

In der Region um Ansbach und Fürth saßen 1948 die von den amerikanischen Offizieren eingesetzten, gänzlich unbelasteten Bürgermeister und Landräte fest im Sattel. Bornkessel, Hörndlein, Neff und Wiesinger - sie alle blieben bis in die sechziger Jahre im Amt. Lediglich Körner mußte 1950 seinen Platz für Böhner räumen ${ }^{152}$. Von den 82 Bürgermeistern des Landkreises Ansbach, die 1948 amtierten, hatten 14 ( = 17 Prozent) der NSDAP angehört, zehn davon waren schon während der NS-Zeit im Amt gewesen. Unter den 34 Bürgermeistern des Landkreises Fürth befanden sich fünf ( $=14$ Prozent) ehemalige Mitglieder der NSDAP. Im neugewählten Stadtparlament von Fürth lag der Anteil von Pgs deutlich unter 10 Prozent, im Ansbacher Stadtrat etwas über 10 Prozent $^{153}$. Die politische Kontrolle über die ehemaligen Parteigenossen in den Ämtern blieb alles in allem also gewahrt und konnte umso leichter aufrecht erhalten werden, als die führenden Beamten nach der korrumpierenden Indienstnahme durch die Nationalsozialisten den früheren Anspruch verloren hatten, die Stadt oder sogar den Staat zu repräsentieren. Außerdem hätte jeder, der es wagte, die Wiederbelebung nationalsozialistischer Ideen zu propagieren, im öffentlichen Dienst einen schweren Stand gehabt und es riskiert, sich politisch und moralisch zu isolieren. Tatsächlich bestand in den Anfangsjahren der Bundesrepublik kaum je Anlaß von oben her wegen solcher Gefahren einzuschreiten. Von den wiedereingestellten Mitläufern des Nationalsozialismus ging - wie wir auch an anderer Stelle noch sehen werden $^{154}$ - keine ernsthafte Gefahr für den demokratischen Neubeginn aus ${ }^{155}$.

\footnotetext{
${ }^{151}$ Special Report der Intelligence Division über Ex-Nazis in the Bavarian Elections, undatiert (1948) in: NA, RG 260, 10/109-1/17.

${ }^{132}$ Vgl. Fränkische Landeszeitung vom 19. Juli 1950.

${ }^{153}$ Vgl. Weekly Intelligence Report, Ansbach Office, 16. Juni 1948, in: NA, RG 260, 9/143-1/6; Annual Hist. Rep., Det. Fürth, 1. Juli 1947-Juni 1948, in: NA, RG 260, 9/96-3/11.

154 Siehe S. 163.

${ }^{155}$ Vgl. hierzu Henke, Die Grenzen der politischen Säuberung in Deutschland nach 1945, S. 132.
} 